\title{
Usage of Evidence Based Medicine Resources in Clinically Practicing Athletic Trainers
}

Kenneth G. Faldetta

West Virginia University

Follow this and additional works at: https://researchrepository.wvu.edu/etd

\section{Recommended Citation}

Faldetta, Kenneth G., "Usage of Evidence Based Medicine Resources in Clinically Practicing Athletic Trainers" (2014). Graduate Theses, Dissertations, and Problem Reports. 166.

https://researchrepository.wvu.edu/etd/166

This Thesis is protected by copyright and/or related rights. It has been brought to you by the The Research Repository @ WVU with permission from the rights-holder(s). You are free to use this Thesis in any way that is permitted by the copyright and related rights legislation that applies to your use. For other uses you must obtain permission from the rights-holder(s) directly, unless additional rights are indicated by a Creative Commons license in the record and/ or on the work itself. This Thesis has been accepted for inclusion in WVU Graduate Theses, Dissertations, and Problem Reports collection by an authorized administrator of The Research Repository @ WVU. For more information, please contact researchrepository@mail.wvu.edu. 
Usage of Evidence Based Medicine Resources in Clinically Practicing Athletic Trainers.

Kenneth G. Faldetta, ATC

Thesis submitted to

College of Physical Activity and Sports Science

at West Virginia University

in partial fulfillment of the requirements

for the degree of

Master of Science

in

Athletic Training

Michelle A. Sandrey, PhD, ATC, Chair

Benjamin Moorehead, MD

Damien Clement, PhD, ATC

Department of Sport Sciences

Morgantown, WV

2014

Key words: evidence based practice, PICO, clinical question, barriers 


\begin{abstract}
Usage of Evidence Based Medicine Resources in Clinically Practicing Athletic Trainers.
\end{abstract}

\author{
Kenneth G. Faldetta, ATC
}

Context: Evidence based medicine (EBM) is a commitment to utilizing a combination of the best available evidence, clinical expertise, and patient preferences to inform clinical decisions. The primary goal of EBM is to provide the highest quality care to patients. Clinicians who do not utilize an evidence-based approach to clinical practice run the risk of denying patients potentially beneficial treatment options. Efficient access to evidence based resources is a crucial part of appropriately implementing EBM in athletic training practice. Therefore, poor accessibility could be a major barrier to implementing an evidence-bases approach to clinical practice in athletic training. Objective: The purpose of this study is to examine the how practicing athletic trainers' (ATs) access literature within the participant's clinical setting. Additionally, a second purpose is to determine the AT's ability to formulate clinical research questions in order to find information related to participant's patient population. Lastly, to examine whether ATs are utilizing evidence based sources (Journal Articles, Databases, and Textbooks) and non-evidence based sources (colleagues, internet forums, and anecdotal evidence) when looking for information to assist clinical decision making. Design: This is a prospective exploratory questionnaire analysis. Setting: Clinically practicing ATs across the United States Patients and Other Participants: A total of 155 (15.5\% returned) clinically practicing ATs participated in the study. Participants were selected from a randomized list of 1,000 National Athletic Trainers' Association (NATA) members who are "certified" membership status. Participants who were "certified student" or "certified retired" were excluded from the study. Of the 155 surveys returned, there was a fair distribution of male $(49 \%, \mathrm{n}=76)$ to female $(51 \%, \mathrm{n}=79)$ participants. The majority of participants were employed in the collegiate setting $(38.7 \%, \mathrm{n}=60)$ and the high school setting $(35.5 \%, n=55)$. The number of years as a Board of Certification certified AT was made up largely by individuals whom had been certified between $0-5$ years $(23.9 \%, n=37)$ and ATs whom have been certified for 21 years or longer $(25.8 \%, \mathrm{n}=40)$. Of ATs surveyed, nearly half $(48.4$, $\mathrm{n}=75$ ) of the participants had been serving as the athletic trainer at their clinical site for 0-5 years. Intervention: Participants were contacted via the National Athletic Trainers' Associated Research Survey Service via e-mail and provided a link to the cover letter and questionnaire. Two weeks after the initial contact, the participants received a follow-up cover letter and questionnaire to encourage participation or thank the participants for their participation. Main Outcome Measures: Usage of EBM versus non-EBM resources and accessibility of evidence-based resources assessed via an online questionnaire. Results: Nearly all of ATs surveyed did have access to current research through professional journals $(96.8 \%, \mathrm{n}=150)$ internet, and applicable databases $(91.6 \%, \mathrm{n}=142)$. Of those who did not have sufficient access, between $(65.2 \%, \mathrm{n}=101)$ of participants cited most commonly no subscription to medical or allied health journals as the barrier to applicable research. The mean response $(1.06 \pm 0.87)$, indicated participants trended 
toward "Agree" in their confidence in finding information applicable to their patient population. Perceived support of employers to use current evidence in clinical practice had a mean response of $(0.84 \pm 0.90)$. Of the internet resources utilized for across all 5 scenarios, the most commonly utilized internet resources included: Google $(36.0 \%, \mathrm{n}=56)$ and PubMed $(33.4, \mathrm{n}=52)$. The number of keywords selected were very comparable amongst four of the scenarios for clinical question 1 (3.72 \pm 1.50$)$, clinical question 2 (3.37 \pm 1.06$)$, clinical question $3(3.71 \pm 7.23)$ and clinical question 4 (3.42 \pm 1.10$)$. Clinical question 5 demonstrated an average of $(3.53 \pm 1.738)$ which is consistent with the forced choice options for the other four scenarios. Chi Squares were conducted to determine relationships between EBM training, accessibility, perceived confidence, and employer support. There was a significant relationship between availability of evidence based resources via professional journals and employment settings $\left(\chi_{1,155}^{2}=9.394, \mathrm{P}=0.050\right.$, $\mathrm{cc}=0.239)$. Training in $\mathrm{EBM}\left(\chi_{1,155}^{2}=76.087, \mathrm{P}=0.001, \mathrm{cc}=0.574\right)$ and $\mathrm{PICO}\left(\chi_{1,155}^{2}=49.957\right.$, $\mathrm{P}=0.001, \mathrm{cc}=0.494)$ both had a significant relationship on access to internet and internet databases. There was a statistically significant relationship between employer support and access to internet and internet databases $\left(\chi_{1,155}^{2}=98.459, \mathrm{P}=0.001, \mathrm{cc}=0.623\right)$ but no significant relationship in access to professional journals $\left(\chi_{1,155}^{2}=7.803, \mathrm{P}=0.167, \mathrm{cc}=0.219\right)$.A significant difference was found between confident in finding EBM resources and internet and internet databases $\left(\chi_{1,155}^{2}=95.86, \mathrm{P}=0.001, \mathrm{cc}=0.618\right)$. PubMed, Ebsco Host, and Cochrane were valued at " +1 " for an EBM resource. Google and Internet Forums were "-1" for a non-evidence based resource. Other was valued at "0" as the responses were both EBM and non-EBM resources. The scenarios that reflected the highest amount of evidence based resources was scenario $2(0.13)$ and scenario 5 (0.12) regarding concussions and chronic ankle instability, respectively. Conclusions: Based on this information gathered through this prospective exploratory study, the majority of ATs have sufficient access to professional literature and knowledge of EBM concepts, but EBM is still not being utilized in the clinical setting. Despite high levels of accessibility to evidence-based resources the usage of non-evidence based resources remains high among ATs in all clinical settings. Resources such as Google and internet forums are most convenient but often do not contain high levels of evidence. Athletic trainers must be cautioned when utilizing non-evidence based resources and encouraged to seek out the best possible evidence available when looking for guidance for clinical decision making. This is suggestive that obstacles exist between EBM education and clinical application. Further education is required to educate ATs about the importance of EBM, translating conceptual EBM to practical applications, for the primary purpose of improving patient care and encouraging the growth of the athletic training profession. 


\section{ACKNOWLEDGEMENTS}

To my family

Thank you to my wonderful family who have supported me in all of my endeavors. Without your love and support, none of this would be possible.

To Dr. Sandrey

Thank for you constant support and guidance throughout this entire process. I would not have been able to finish this project without it.

To Dr. Moorehead and Dr. Clement

Thank you for volunteering your valuable time to serve as committee members for this thesis. The expertise and insight you provided was invaluable in the creation of this project.

To my classmates

Thank you for an incredible two years. I have met people and made memories that I will always cherish. 


\section{TABLE OF CONTENTS}

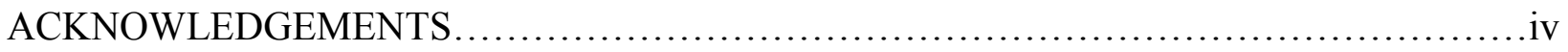

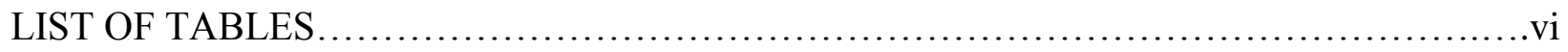

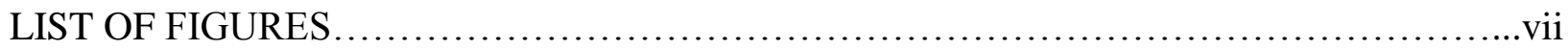



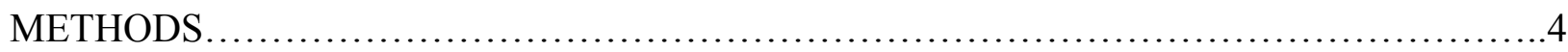

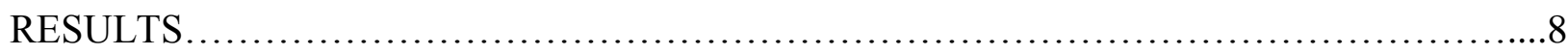

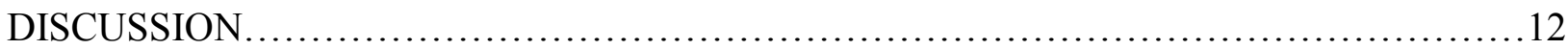

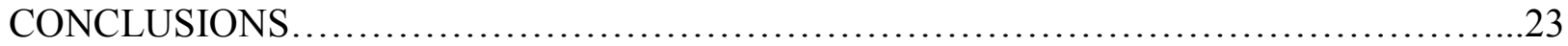

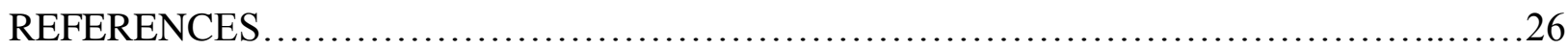

APPENDICIES

APPENDIX A. THE PROBLEM..............................................

APPENDIX B. LITERATURE REVIEW ......................................... 39

APPENDIX C. ADDITIONAL METHODS ......................................55

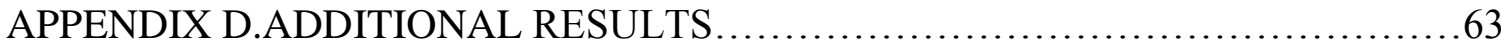

APPENDIX E. RECOMMENDATIONS FOR FUTURER RESEARCH...............73

ADDITIONAL REFERENCES ...................................................... 74 


\section{LIST OF TABLES}

TABLE

PAGE

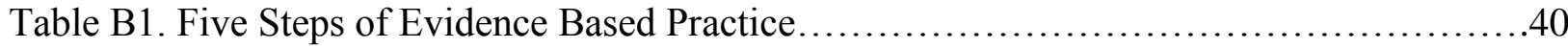

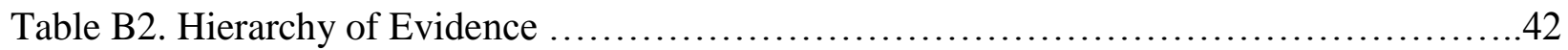

Table B3. Graded Approach for Grading Quality Evidence...............................43

Table C1. Initial Cover Letter to Certified Athletic Trainers................................55

Table C2. Survey to Certified Athletic Trainers......................................56

Table C3 Follow-up Cover Letter to Certified Athletic Trainers............................62

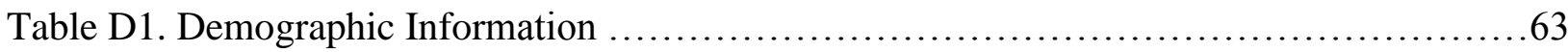



Table D3. Accessibility and Knowledge of EBM Resources..............................64

Table D4. Most Important EBM Concepts ..........................................65

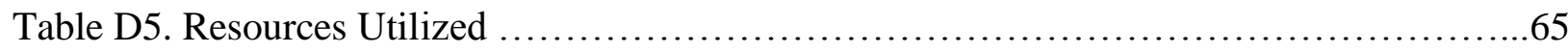

Table D6. Internet Resources Utilized ..............................................65

Table D7. Usage of EBM versus Non-EBM resources..................................65

Table D8. Chi Square: Employment Setting and Professional Journals......................66

Table D9. Chi Square: Employer Support and Accessibility of EBM Resources...............66

Table D10. Chi Square: Confidence of finding EBM resources and Accessibility...............66 


\section{LIST OF FIGURES}

FIGURE PAGE



Figure D4. PICO Training.........................................................

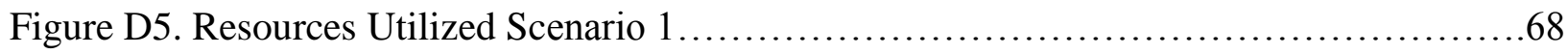

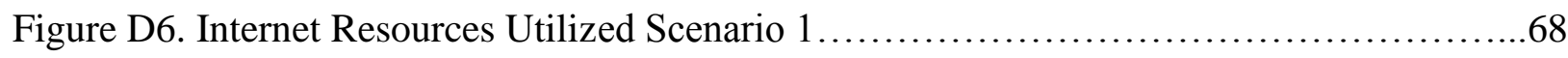

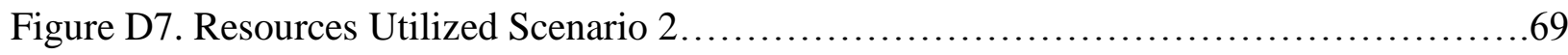

Figure D8. Internet Resources Utilized Scenario $2 \ldots \ldots \ldots \ldots \ldots \ldots \ldots \ldots \ldots \ldots \ldots \ldots \ldots \ldots \ldots$

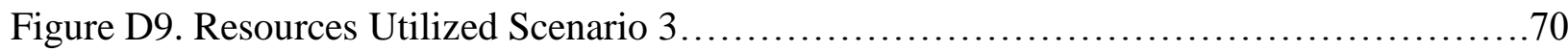

Figure D10. Internet Resources Utilized Scenario $3 \ldots \ldots \ldots \ldots \ldots \ldots \ldots \ldots \ldots \ldots \ldots \ldots \ldots \ldots$

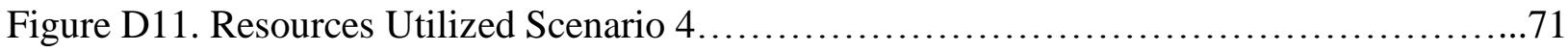

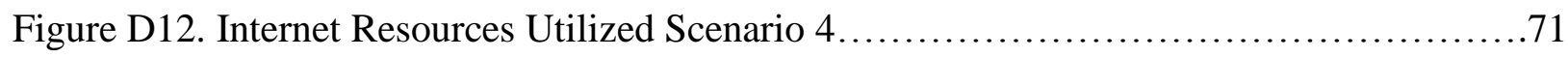








\section{INTRODUCTION}

Evidence Based Medicine (EBM) is the "integration of the best research evidence with

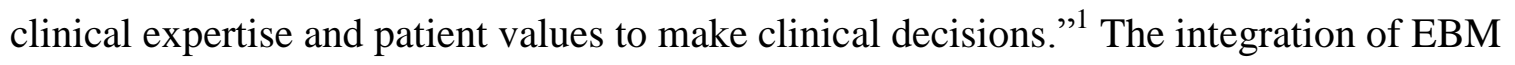
techniques allows clinicians to effectively ask clinical questions and find quality research regarding the effectiveness of the treatment and management of patient conditions. ${ }^{1-4}$ This process encourages clinicians to continue to seek out different treatment methods scientifically supported by literature that they may not have utilized otherwise. ${ }^{1,3}$ If this process does not occur patients may be denied the benefits of new and potentially beneficial therapeutic options. ${ }^{2}$ Health care has moved beyond the days of making clinical decisions in the absence of evidence or making clinical decisions based on anecdotal evidence alone. Steves et al. ${ }^{3}$ stated that "literature is constantly changing and the best method of practice may change next year." Therefore, in order to provide the highest quality care to patients it is of paramount importance that ATs become constant consumers of the literature.

Allied healthcare fields such as nursing, physical therapy, and occupational therapy have already adopted EBM into clinical practice. ${ }^{3,5,6}$ Evidence based medicine was recently integrated into the $5^{\text {th }}$ edition of the National Athletic Training Education Competencies which stated that all undergraduate athletic training students must have an understanding of EBM concepts prior to graduating from a Commission on Accreditation of Athletic Training Education (CAATE) accredited undergraduate program. ${ }^{7}$ The educational competencies stress a five step approach to evidence based. The effectiveness of EBM has been demonstrated in other allied healthcare professions including physical therapy and nursing. ${ }^{3,5,6}$ In order for Athletic Training to continue to develop and remain current among other allied healthcare professionals, it is essential EBM also be adopted. ${ }^{3}$ 
The ability of healthcare providers to practice EBM rests heavily on the clinician's knowledge of EBM concepts and the access to evidence based resources. ${ }^{8,9}$ As internet access in homes, offices, and via cell phones is becoming increasingly more common the amount of evidence-based resources available to clinicians has also been drastically increased. ${ }^{9,10}$ The development of electronic information resources including PubMed, MEDLINE, EMBASE, and Cochrane Library of databases have allowed clinicians to access robust sources of information. ${ }^{2,12}$

Accessibility to evidence based resources is crucial to implementing evidence based resources into clinical practice. If evidence based resources are not readily available, clinicians may utilize more convenient and non-evidence based resources such as colleagues and websites. A study by Jette et al. ${ }^{5}$ found that $93 \%$ of physical therapists had access to evidence based resources including professional journals either in paper or electronic form. However, participants reported reading less than 5 articles per month despite high levels of accessibility. Sackett et al. ${ }^{1}$ stated that physical therapists look to non-evidence based resources such as colleagues rather than consult literature for information to aid clinical decision making. ${ }^{1,7}$ Similarly, it is often assumed that athletic trainers (ATs) also have sufficient access to evidence based resources. McCarthy et al. ${ }^{10}$ stated that $97.7 \%$ and $98.5 \%$ of 1209 ATs surveyed had direct access to textbooks and websites, respectively. However, access varied significantly between individuals affiliated with academia (program directors, professional educators, and postprofessional students) and those who were not. Affiliation with academia also affected the clinician's ability to access and utilize MEDLINE, CINAHL, Cochrane Library, or PubMed databases. ${ }^{11}$ More than $90 \%$ of academic ATs had access to these medical databases whereas only $66.8 \%$ of clinicians without academic affiliation had the same access. ${ }^{11}$ Thus, ATs 
practicing outside of the collegiate setting or without affiliations with academia may have no access or limited access to full text searchable databases such as MEDLINE, SPORTDiscus, or CINAHL. ${ }^{11,13}$ Efficient access to evidence based resources is a crucial part of appropriately implementing EBM in athletic training practice. ${ }^{6,10,13}$ Therefore, ATs who work in a private clinic, secondary school, industry, or physician's office may have decreased access to literature to provide answers to clinical questions compared to those associated with academia. ${ }^{13}$

Athletic trainers must seek out evidence based resources in order to improve clinical outcomes. ${ }^{1,4,12}$ Healthcare has surpassed the time of making clinical decisions based on what was traditionally done or what outdated research suggested. In order to provide the highest quality care for patients, ATs must adopt EBM concepts. It is unclear why ATs are still not utilizing EBM concepts in clinical practice. ${ }^{11,14}$ Furthermore, it is paramount to determine whether these individuals are not utilizing EBM in clinical practice due to lack of accessibility to evidence based resources such as MEDLINE, PubMed, CINAHL or lack of training in EBM to effectively apply the concepts into clinical practice. ${ }^{3,12,13}$ Athletic trainers should have adequate accessibility to evidence based resources to be able to utilize current evidence in clinical practice. Therefore, the purpose of this study will be to examine the how practicing ATs' access literature within the participant's clinical setting. Additionally, a second purpose is to determine the AT's ability to formulate clinical research questions in order to find information related to participant's patient population. The final purpose is to examine whether ATs are utilizing evidence based sources (journal articles, databases, and textbooks) and non-evidence based sources (colleagues, internet forums, and anecdotal evidence) when looking for information to assist clinical decision making. 


\section{METHODS}

Design

This is a prospective exploratory study that included data collected from a 34- 42 item online questionnaire. The number of questions answered by participants is variable based on the answers to accessibility to the internet and professional journals. If the participant has sufficient access, the participant was prompted to elaborate the on resources utilized. If the participant did not have sufficient access, the participant was prompted to elaborate on the barriers experienced. The levels of accessibility of EBM resources and the types of resources being utilized among certified ATs was evaluated. This research also explored the ability of certified ATs to develop clinical research questions related to clinical practice. Lastly, the type of resources (EBM or nonEBM resources) utilized by clinically practicing ATs was also be explored.

\section{Participants}

The participants of this study were randomly selected via the National Athletic Trainers' Association Research Survey Service. A sample of 1,000 randomly selected National Athletic Trainers' Association were selected based on members being listed as certified membership status. Participants were included from districts $1-10$ expanding across the United States. This approach was taken to avoid any sampling bias and insure geographical equality. A total of 155 of 1,000 clinically practicing ATs responded to the Usage of EBM resources survey. Thus, the response rate was 15.5 percent. Participants excluded from this study will be certified students including graduate assistants, non-certified ATs, non-certified students, retired ATs, and ATs practicing outside the United States. This study was approved by the Institution's Office of Research Compliance. 


\section{Instrumentation}

The questionnaire was developed through an objective review of the literature by examining questions and wording utilized in previous evidence based research studies. ${ }^{5,6,8,10,13}$ The focus of the questionnaire was to assess the levels of accessibility of EBM resources, resources utilized, and the ability to formulate clinical questions. The questionnaire consisted of 43 questions. The questionnaire consisted of including demographics, accessibility of evidence based resources, confidence in the ability to locate applicable research evidence, perceived support of EBM in the participant's employment setting, presence of previous EBM training, types of resources being utilized, and development of search terms. The length of the questionnaire was variable based on the responses to questions regarding participants' access and barriers to resources. The demographic section of the questionnaire surveyed age, athletic training setting of employment, number of years at the participant's employment site, and number of years of Board of Certification (BOC) certified status, and prior training in EBM or PICO. If participants noted training in PICO or EBM, where the training had been received was included. The questions included in this section included 13 "forced choice" questions and one "rank scale" question on a scale of 1-3 (1 being the most important and 3 being the least important). The accessibility questions examined whether the participants had access to current research through professional journals, databases, and internet. Additional questions assessed whether participants are familiar with utilizing allied healthcare databases, confidence in finding applicable research evidence, support of evidence based practice at the participant's employment setting, and whether the participant has any formal training in the PICO framework. Lastly, the scenario section consisted of 5 case reports involving the need for participants to seek out current research evidence to find answers to clinical questions. The case report question format is meant 
to simulate clinical questions that ATs may face within clinical practice. The scenarios highlight the following domains of athletic training: clinical evaluation, rehabilitation, treatment, and prevention. Following each case report, there are 4 questions repeated for each scenario. For the first four case reports, there are two forced choice questions with five possible choices and two "select all that apply" questions with 5 and 7 possible responses. The final case report, there is one forced choice, one open-ended question, and two "select all that apply" questions with 5 and 7 possible responses.

The questionnaire was reviewed by four certified ATs for readability and clarity. The questionnaire was pilot tested by 8 graduate athletic training students prior to distribution. A psychometric expert experienced in research, questionnaires, and surveys assisted in the development of the survey and reviewed for content and face validity. Procedures

The sample of 1,000 certified ATs were randomly selected via the National Athletic Trainers' Association Research Survey Service. The participants were contacted and surveys were distributed through the Research Survey Service.

The link to the questionnaire was sent via e-mail to the certified ATs selected to participate. The e-mail included a brief description of necessary background information, and a link that directed the participant to Survey Monkey. Once clicking on the hyperlink, participants were taken to the survey on Survey Monkey. At this time, participants were prompted with the cover letter (Table $\mathrm{C} 1$ ) explaining the procedures of the questionnaire, what directions to follow should participants be willing to participate, and the rights of the participant. Immediately following the cover letter, the participants were be prompted to select whether or not to continue to the survey. (Table C2) A follow-up e-mail was sent via the NATA Research Survey Service to 
all participants approximately two weeks following the initial email to selected certified ATs to further encourage participation. (Table C3) The participants were contacted in February 2014. Data Analysis

The data analysis of the accessibility and knowledge questionnaire was divided into three categories (demographic information, accessibility, case scenarios, and Pearson Chi Squares). All survey responses were compared based on knowledge and accessibility on case reports. Furthermore, responses were compared based on prior knowledge of EBM, prior knowledge of PICO, accessibility across clinical settings, support of current research within the clinical setting, and number of years certified. Analysis of the Likert scale questions was assessed by assigning a numerical value for Strongly Disagree (-2), Disagree (-1), Neutral (0), Agree (+1), and Strongly Agree (+2).

The five scenarios were analyzed based participants responses to the associated questions to determine common tendencies of responses for each given case report. The open-ended question associated with case report 5, were analyzed for a common propensity. Due to an inability to objectively discern between the participants intention to utilize search terms within the PICO format. The five case report answers were compiled to determine a total frequency for statistical testing. The number of keywords utilized for each case report including the open ended question for case report 5 was assessed to compare means. Assessing the number of keywords utilized for case 5 was performed by counting the number of words or phrases. For example, "Chronic Ankle Stability" was counted as one keyword as it is a single phrase rather than three individual words. An example of three individual key words are "Rehabilitation, Ankle, and Prevention." Numerical values were assigned to the resources utilized for all case reports in order to compare evidence based resources versus non-evidence based resources. Evidence based 
resources (PubMed, EBSCO, and Cochrane) were valued a +1 and non-evidence based resources (Google and Internet Forums) were valued at -1 . The question option "Other" was placed at 0 as the participants could have filled in either an EBM or non-EBM resource.

Statistical Analysis

Descriptive statistics were conducted including means, frequencies, and standard deviations. Chi Squares were performed to determine likelihood of demonstrating common themes among ATs resourced accessed based on the availability of resources, knowledge, and presence of PICO training. A P-value of $\mathrm{P}=0.05$ will be used for all analysis. All statistical analysis will be performed utilizing IBM-SPSS Version 23.0 for Windows (IBM-SPSS, Chicago, IL.)

\section{RESULTS}

Demographic

Of the 155 surveys returned, there was a fair distribution of male $(49 \%, n=76)$ to female $(51 \%, \mathrm{n}=79)$ participants. The majority of participants were employed in the collegiate setting $(38.7 \%, \mathrm{n}=60)$ and the high school setting $(35.5 \%, \mathrm{n}=55)$. The number of years as a Board of Certification certified AT was made up largely by individuals whom had been certified between 0-5 years $(23.9 \%, \mathrm{n}=37)$ and ATs whom have been certified for 21 years or longer $(25.8 \%$, $\mathrm{n}=40)$. Of ATs surveyed, nearly half $(48.4, \mathrm{n}=75)$ of the participants had been serving as the AT at their clinical site for 0-5 years. See Table D1 for additional Demographic information.

Of the ATs surveyed, greater than half $(56.8 \%, \mathrm{n}=88)$ had some form of education or training in EBM. The majority of the ATs whom had education in EBM reported receiving education from professional seminars $(57.6 \%, \mathrm{n}=49)$ and graduate education $(55.3 \%, \mathrm{n}=47)$. Education in Patient, Intervention, Comparison, Outcome (PICO) framework was low. Nearly 
$75 \%(73.5 \%, \mathrm{n}=114)$ of the ATs surveyed did not have PICO training or education. The number of ATs who had training or education in the PICO obtained this from graduate education (50\%, $\mathrm{n}=15)$ and professional seminars $(50 \%, \mathrm{n}=15)$. See Table D2, Figure D1, and D2 for PICO and EBM Training information for additional results.

\section{Access to EBM Resources}

Nearly all of ATs surveyed did have access to current research through professional journals $(96.8 \%, \mathrm{n}=150)$ internet, and applicable databases $(91.6 \%, \mathrm{n}=142)$. Of the participants who did not have access to current research through professional journals, all 5 participants were employed at the high school setting. Of the participants who did not have access to the internet and applicable databases, 2 participants were from high schools and 1 from the sports medicine clinic setting. All participants from the collegiate setting cited access to both professional journals, internet, and applicable databases. The familiarity with medical and allied health databases was high $(80.6 \%, \mathrm{n}=125)$. See Table D3, Figure D3, and D4 for additional results regarding accessibility of internet, internet databases, and professional journals.

Participants were asked to rate their confidence in their ability to find applicable research related to their patient population. This was calculated utilizing "Strongly Disagree" as -2 and "Strongly Agree" as +2 and 0 as Neutral to achieve a numerical output for statistical analysis. The mean response was $1.06 \pm 0.87$, as participants trended toward "Agree" in their confidence in finding information applicable to their patient population. Similarly, the perceived support of employers to use current evidence in clinical practice had a mean response of $0.84 \pm 0.90$. Thus, when asked about support from their employers, the responses ranged between "Agree" and "Neutral." Athletic trainers surveyed about the perceived importance of the three components of EBM (1- Most Important - 3 Least Important) ranged from clinician expertise $(58.7 \%, \mathrm{n}=84)$ as 
most important followed by current research $(24.5 \%, \mathrm{n}=35)$, and lastly patient preference $(16.8 \%, \mathrm{n}=24)$. See Table D4 for additional results regarding importance of EBM concepts. Case Scenarios

The case scenarios 1-4 were assessed to determine the number of keywords typically utilized by ATs when creating clinical questions. All case scenario clinical questions except number 5 included force choice options of between 1 keyword to 5 keywords. The number of keywords selected were very comparable amongst four of the scenarios for clinical question 1 $(3.72 \pm 1.50)$, clinical question $2(3.37 \pm 1.06)$, clinical question $3(3.71 \pm 1.23)$ and clinical question 4 (3.42 \pm 1.10$)$. Clinical question 5 was a fill in the blank response to assess whether ATs creating a research question would vary from the forced choice options. Clinical question 5 demonstrated an average of $(3.53 \pm 1.738)$, which is consistent with the forced choice options. When asked what resources the participant would utilize to find information related to the scenario questions, the most commonly cited resources included: colleagues, internet databases, and journal articles. See Table D5 and D6 for individual responses for resources and internet resources associated with each scenario. Based on these responses, ATs trended towards nonevidence based resources such as colleagues more frequently than evidence based resources such as journal articles and internet databases. See Figures D6-14 for additional results related to resource and internet resources used for each clinical scenario. The majority of ATs reported that they had sufficient access to research applicable to their patient population through professional journals $(96.77 \%, \mathrm{n}=150)$ as well as internet and internet databases $(82.78 \%, \mathrm{n}=125)$. Of those who did not have sufficient access, between $(65.20 \%, \mathrm{n}=12)$ of participants cited most commonly no subscription to medical or allied health journals as the barrier to applicable research. Of the internet resources utilized for the scenarios the most commonly utilized 
resources included: Google (36.02, n=95) and PubMed (33.38, n=88). Throughout all scenarios, Google was the most commonly cited internet resource utilized to find research applicable to the patient population despite yielding results that are both evidence and non-evidence based. The number of evidence and non-evidence based resource utilized was assessed for each case scenario. PubMed, Ebsco Host, and Cochrane were valued at "+1" for an EBM resource. Google and Internet Forums were "-1" for a non-evidence based resource. Other was valued at " 0 " as the responses were both EBM and non-EBM resources. The scenarios that reflected the highest amount of evidence based resources was scenario 2 (0.13) and scenario $5(0.12)$ regarding concussions and chronic ankle instability, respectively. Additional results regarding the number of EBM versus non-evidence based resources can been viewed in Table D7.

\section{Pearson Chi Squares}

Pearson Chi Squares were completed to explore relationships between employment setting, availability of EBM resources (professional journals, internet access, and internet databases), EBM training (PICO and/or EBM education), employer support, confidence in finding applicable research, and perceived importance of EBM components (patient preference, clinician expertise, and current research).

There was a significant relationship between availability of evidence based resources via professional journals and employment settings $\left(\chi_{1,155}^{2}=9.394, \mathrm{P}=0.050, \mathrm{cc}=0.239\right)$. However, there was no difference in availability of internet databases, and internet access throughout employment settings $\left(\chi_{1,155}^{2}=8.286, \mathrm{P}=0.406, \mathrm{cc}=0.225\right)$. There was also no significant relationship between barriers to accessibility and employment setting: no internet access $\left(\chi_{1}^{2}\right.$, $\left.{ }_{155}=1.830, \mathrm{P}=0.767, \mathrm{cc}=0.108\right)$, no computer access $\left(\chi_{1,155}^{2}=1.830, \mathrm{P}=0.767, \mathrm{cc}=0.108\right)$, and lack of journal subscription $\left(\chi_{1,155}^{2}=2.245, \mathrm{P}=0.325, \mathrm{cc}=0.119\right)$. Training in $\operatorname{EBM}\left(\chi_{1,155}^{2}=76.087\right.$, 
$\mathrm{P}=0.001, \mathrm{cc}=0.574)$ and PICO $\left(\chi_{1,155}^{2}=49.957, \mathrm{P}=0.001, \mathrm{cc}=0.494\right)$ both had a significant relationship on access to internet and internet databases. There was no significant difference in access to professional journals for $\operatorname{EBM}\left(\chi_{1,155}^{2}=1.183, \mathrm{P}=0.554, \mathrm{cc}=0.087\right)$ nor $\mathrm{PICO}$ training $\left(\chi_{1,155}^{2}=0.330, \mathrm{P}=0.848, \mathrm{cc}=0.046\right)$. Analysis was also conducted to determine the relationships between employment support for utilization of EBM and accessibility to professional journals, internet, and internet databases. There was a statistically significant relationship between employer support and access to internet and internet databases $\left(\chi_{1,155}^{2}=98.459, \mathrm{P}=0.001\right.$, $\mathrm{cc}=0.623)$ but no significant relationship in access to professional journals $\left(\chi_{1,155}^{2}=7.803\right.$, $\mathrm{P}=0.167, \mathrm{cc}=0.219)$. See Table D9 for results regarding employment support and access to EBM. Lastly, there was no significant relationship between confidence in finding EBM resources and access to journals $\left(\chi_{1,155}^{2}=4.198, \mathrm{P}=0.521, \mathrm{cc}=0.162\right)$. A significant difference was found between confident in finding EBM resources and internet and internet databases $\left(\chi_{1,155}^{2}=95.86\right.$, $\mathrm{P}=0.001, \mathrm{cc}=0.618$ ). See Table D10 for results for confidence and accessibility of EBM resources.

\section{DISCUSSION}

The purpose of this study was to provide an assessment of how clinically practicing ATs utilize EBM, search for applicable resources, and what resources are being utilized to assist in clinical decision making. Athletic trainers responded to an online questionnaire assessing participant's accessibility to a computer, the internet, internet databases, and professional journals at their employment setting. Questions were also asked to determine the usage of evidence based and non-evidence based resources. Lastly, the ability of the clinician to create clinical research questions that will yield clinically applicable results. 
The results of this questionnaire highlighted that lack of education and accessibility are no longer the primary barriers preventing ATs from using EBM in clinical practice. Evidence based medicine education and/or training is becoming increasingly more common in athletic training. PICO training remains low but ATs were able to effectively formulate clinical questions utilizing keywords for case scenarios provided. Evidence based medicine and PICO training was most commonly received in graduate education and professional seminars. The usage of online modules was surprisingly low amongst ATs despite being a free resource. Accessibility was very high across all employment settings for access to both professional journals and internet databases. Also, the confidence of ATs in their ability to find professional literature related to their clinical site as well as familiarity with medical/allied health databases was high. Despite ATs possessing the necessary knowledge and access to evidence based resources, the usage of EBM resources was low. The most commonly cited resources amongst ATs to aid clinical decision making were Google and colleagues. Assessment of evidence based resources versus non-evidence based resources demonstrated that ATs are utilizing non-EBM and EBM resources equally. There was very minimal variability between the types of resources utilized between the case scenarios suggesting that ATs use the same resources regardless of case topic. However, scenarios highlighting chronic ankle instability and concussion management demonstrated the highest levels of evidence-based resource utilization. The increased use of evidence based resources in the specific case scenarios may reflect the high amounts of evidence-based resources available in those subject areas.

Evidence based medicine has been researched from an academic perspective but there has been no research conducted that directly ties EBM to clinical athletic training. Recent research in athletic training has focused on knowledge, attitudes, accessibility, barriers, and 
educational interventions. ${ }^{10,13,15-17}$ The profession of athletic training has been shifting towards an EBM paradigm. Therefore, the ability to identify why EBM is not translating from academia to clinical practice is very important. Uncovering potential barriers preventing EBM utilization will help provide solutions to potential obstacles and move closer to athletic training becoming an evidence based profession.

Chi Squares demonstrated both relationships and lack of relationships between employment setting, accessibility, employer support, confidence in finding research, PICO training, and EBM training. No relationship was demonstrated between employment setting and the barriers experienced to professional literature. This echoes that accessibility to evidencebased resources is no longer a barrier to implementation in any employment setting. Thus, the ability to access evidence-based resources is equal across all ATs regardless of clinical setting. There was a relationship between employer support for EBM and accessibility to the internet and applicable databases. This further emphasizes the importance of administrative support for the utilization of EBM in clinical practice. If the administration feels that EBM is important to improving patient outcomes, evidence-based resources will more likely be available to ATs to implement into clinical practice. A relationship was also demonstrated between both EBM and PICO training, and accessibility to internet and applicable databases. With increased knowledge of EBM and PICO, athletic trainers will be made more aware of the resources available and will more effectively utilize the resources at their clinical site in order to find information relevant to their patient population. Lastly, a relationship between participant's confidence in finding applicable research and accessibility of internet and internet database was noted. This relationship is suggestive that if athletic trainers are familiar and comfortable with the resources 
available at their clinical site, they will have a greater ability to utilize and to find evidence-based resources.

Knowledge of Evidence Based Medicine

Of the ATs surveyed in this study, greater than half of ATs surveyed stated that they had received some kind of EBM training or education. Hankemeier et al. ${ }^{13}$ and McCarthy et al. ${ }^{10}$ assessed knowledge of EBM. Knowledge reflected in these studies was considered low when the study was conducted in spring of 2010. Four years have passed since the publication of these studies and the implementation of EBM concepts in the NATA $5^{\text {th }}$ edition education competencies. ${ }^{6,1013}$ Despite this implementation, there was a higher level of usage of professional seminars and graduate education to gain EBM knowledge rather than undergraduate education and online modules. Evidence based medicine education was not integrated into the undergraduate curricula until 2011 with $5^{\text {th }}$ edition NATA education competencies. ${ }^{6}$ Thus, it is possible that the ATs surveyed graduated prior to the implementation as "Certified Student" and "Students" were excluded from this study. It was hypothesized that the usage of online modules for EBM education would be higher as the NATA provides a free two part web-based course titled "Evidence-based Practice in Athletic Training." This was developed by the NATA executive committee for education and is available with or without an NATA membership. ${ }^{14,16}$ Welch et al. ${ }^{15-17}$ stated that online modules were an effective tool for enhancing AT's knowledge of EBM. The lack of utilization of online modules reflects a potential lack in awareness of the educational opportunities available to ATs.

Prior education in PICO was very low in this subject population. Nearly three-fourths did not have any training or education in PICO. The ability to create a clinical question with all the elements of the PICO formation is regarded as the key to efficiently finding high quality 
evidence. ${ }^{17,18,19}$ Huang et al. ${ }^{19}$ stated a well formulated clinical research question will be the difference between obtaining only clinically relevant information and a large amount of information of little to no clinical relevancy. Despite low levels of PICO training, ATs were able to formulate clinical questions using keywords for the case scenarios. The ability to create an effective questions is particularly important when utilizing internet databases such as PubMed. PubMed does not sort search results based on relevancy. ${ }^{2,3}$ Therefore, the search results will be limited if articles do not contain all the necessary criteria and may be lost among an overwhelming amount of literature.

A study by Welch et al. ${ }^{16-17}$ had expressed concerns that the current state of EBM education does not effectively translate from coursework, modules, and workshops to the clinical setting. The goal of EBM in athletic training is to provide the highest quality patient care and continue to advance the profession of athletic training. If the EBM education and training becomes more and more apparent in athletic training without an equal changes in clinical practice, more effective teaching methods may need to be developed. ${ }^{15-17}$ Welch et al. ${ }^{15}$ suggested that integrating scenarios that directly relate to clinical situations an AT could encounter is a critical for EBM to translate to clinical practice. Thus, the scenario based questionnaire may be able to provide valuable insight into how clinical ATs utilize or do not utilize evidence-based practice.

Access to Evidence Based Medicine Resources

Nearly all ATs $(96.8 \%)$ surveyed in this study reported access to current research through professional journals, internet, and internet databases. This finding is an improvement from the study conducted by McCarthy et al. ${ }^{10}$ which found that ATs had above an $89 \%$ for direct access to professional literature. This is also similar to Jette et al. ${ }^{5}$ who reported that $93 \%$ of physical 
therapists had direct access to EBM resources. Thus, the availability of professional literature is comparable between ATs and physical therapists. Availability of resources did vary slightly based on employment setting. The individuals in this study that did not have sufficient access to professional journals, internet, and internet databases were employed in the sports medicine clinic and high school settings. All ATs surveyed in the collegiate setting reported access to professional literature.

McCarthy et al. ${ }^{10}$ also found that affiliation with academia affected the availability and utilization of evidence based resources such as MEDLINE, CINAHL, Cochrane Library, or PubMed. Participants working in the non-academic setting or high school setting frequently have no or decreased access to full text searchable databases. ${ }^{10}$ Without the appropriate access to evidence based resources, clinicians are reliant on non-evidence based resources and anecdotal evidence to make clinical decisions. Of those who did not have sufficient access, the most commonly cited barrier (65\%) was lack of journal subscriptions to medical and allied health journals. This is consistent with McCarthy et al. ${ }^{10}$ and Hankemeier et al. ${ }^{13}$ in that ATs who are not affiliated with academia may be hindered by a lack of access to full text articles compared to those who are affiliated with academia. The Chi Squares conducted in this subject population comparing accessibility to professional literature across employment settings suggested no relationship. Therefore, accessibility to evidence-based resources is equal across all employment settings.

The types of internet resources being utilized in the clinical setting was also assessed in this study. Prior to this, there has been no research conducted to assess whether ATs are seeking out evidence based resources on the internet or non-evidence based resources. Seventy-five percent of ATs cited sufficient access to internet and databases to find current research for their 
patient population. The most commonly utilized internet resources were Google (36\%) and PubMed (33\%). The resources were also combined to determine whether ATs preferred evidence based resources versus non-evidence based resources. PubMed, Ebsco Host, and Cochrane were valued at " +1 " for an EBM resource. Google and Internet Forums were "-1" for a non-evidence based resource. Other was valued at " 0 " as the responses were both EBM and non-EBM resources. In this study, athletic trainers used both non-evidence based and evidence based resources equally with a small trend towards evidence based resources. McGowan et al. ${ }^{12}$ stated clinician's should be cautioned when using generalized search engines such as Google, Bing, or Yahoo as these resources frequently gather non-scientific and low level evidence. ${ }^{12}$ Athletic trainers should be encouraged to utilize the best possible research evidence available in order effectively practice EBM. $^{12}$

As the scenarios were related to typical situations faced in this clinical setting, where information was obtained was of particular concern. The scenarios that reflected the highest number of evidence based resources was scenario 2 and scenario 5 regarding concussions and chronic ankle instability, respectively. This can be attributed to the large body of research available in these subject areas that ATs can reference. ${ }^{20-23}$ The NATA released two position statements highlighting both topics "Conservative Management and Prevention of Ankle Sprains in Athletes" and "Management of Sport-related Concussion." These documents are a compilation of the best available evidence either in support of or refuting the utilization and effectiveness of modalities, rehabilitation techniques, return to activity considerations, and medications. ${ }^{22,23}$ This $^{2}$ is made readily available to all NATA members to help improve clinical practice by considering the most recent literature when treating the AT's patient population. Thus, the usage of EBM 
resources may be higher among ATs for the ankle instability and concussions due to availability of evidence based resources such as position statements and systematic reviews. ${ }^{22-23}$

The participants' confidence in their ability to find applicable research related to their patient population was assessed using a Likert scale. The scale ranged from "Strongly Disagree" to "Strongly Agree" or " -2 " to " +2 ," respectively. The response yielded demonstrated that ATs trended towards "Agree" and "Strongly Agree." Chi Square also demonstrated a relationship between the ability to access internet and internet databases and AT confidence. Thus, ATs feel that they are capable of finding professional literature if required. Athletic trainers have a high level of perceived confidence in finding professional literature and have high levels of accessibility yet the usage of EBM resources remains low. This may be a related to clinicians' attitude toward EBM. Ciliska ${ }^{24}$ reported that participants believe that EBM is only the "flavor of the month" and are hesitant to adopt it as EBM will be short lived.

\section{Case Scenarios}

There has been no prior research conducted regarding the development of clinical questions and resources utilized in a scenario format. Five case scenarios were developed to simulate the usage of EBM in the clinical setting. The five scenarios were developed to highlight the following domains of athletic training: orthopedic evaluation, pharmacological treatment, prevention, diagnostic imaging, and modalities. The most commonly cited resources in descending order across all scenarios included: colleagues, internet databases, and journal articles. The individual scenarios followed the same pattern except for scenario 2 which yielded colleague, journal article, and internet database. Scenario 2 dealt with a neurocognitive testing for concussions, it is possible that ATs value specific journal articles greater than internet databases in that subject area or are more aware of resources such as NATA position statements. 
The frequent utilization of colleagues for information regarding clinical scenario can be an indication that ATs prefer non-evidence based resources as immediate responses are readily available. This is consistent with Jette et al. ${ }^{5}$ and Sackett et al. ${ }^{1}$ that physical therapists prefer the most convenient resources rather than seeking out the best possible evidence despite high levels of accessibility. ${ }^{1,5}$ A similar trend has also been noted among physicians that prefer to find quick references and typically will spend less than 10 minutes searching for resources to answer clinical questions. ${ }^{25-27}$ In search for the highest quality evidence that is applicable to the clinician's patient population, additional time may be required. Hence, time continues to be a barrier to the implementation of EBM. .,2,5,28 $^{1}$

There has been no research conducted regarding the development of clinical research questions among clinically practicing ATs. Within each case scenario, ATs were given an opportunity to develop a clinical question to gain additional information about the case. For scenarios 1-4 participants selected search terms provided in forced choice options. For the final scenario 5, participants were given the opportunity to provide their own key words. This was to assess whether clinicians were asking foreground versus background questions. The average number of search terms utilized throughout all five scenarios was $3.56 \pm 1.289$. According to Hoogendam et al. ${ }^{25}$ increased knowledge on a given subject matter can potentially increase recall based on using more adequate research terms. Without a foundation of knowledge to create appropriate MeSH terms, clinicians may have to seek out background information before seeking out foreground information. ${ }^{25,29}$ Athletic trainers most frequently selected the more specific search terms. Based on the number of search terms utilized, this suggested that the ATs surveyed were familiar with the case scenario topics. For example, ATs more frequently selected “Adolescent, Male, Sever's Disease, Modalities, and Pain” versus “Sever's Disease.” This is 
indicative that ATs more frequently seek out foreground information that is patient centered rather than background information regarding the pathology of Sever's Disease. The numbers of search terms for the forced-choice questions for scenario 1 through 4 were comparable to the open ended question of Scenario 5. Common themes noted in Scenario 5 included: "Chronic Ankle Instability, Rehabilitation, Soccer, Exercises, and Prevention.” This suggested that despite low levels of PICO training ATs are able to create clinical research questions in order to find research related to the patient population at their employment setting.

Clinical Implications

Results from this study suggested that the lack of EBM in the athletic training profession is not due to lack of accessibility to current search nor lack of knowledge of EBM. Additional barriers must exist between EBM education and the application in clinical practice. For individuals who are not affiliated with academia, lack of journal subscriptions was cited as a barrier. Without the appropriate journal subscription the amount of full text information available is greatly decreased for ATs in these settings. In order to accommodate this obstacle, additional methods of obtaining full text articles need to be provided for these individuals. Without a sufficient body of literature to refer to, it will not be possible for these clinicians to find answers to their clinical questions. This could be accomplished by providing pre-appraised literature focusing specifically on clinically meaningful information.

Professional literature must also be presented in a way that clinically practicing ATs can understand the findings and implement them into clinical practice. The average AT may not have a sufficient background in statistical analysis in order to fully understand the results provided in professional literature. Creating more meaningful evidence-based resources may encourage more ATs to use evidence-based resources in place of non-evidence based resources. Athletic trainers 
must use non-evidence based resources with caution. As the information yielded from colleagues, google, and internet forums may not be based on high level evidence.

Additional educational opportunities or increased awareness of the educational opportunities available is necessary. The usage of online modules for EBM education is underutilized. Athletic trainers who do not have any EBM education can utilize a free two part webbased course titled "Evidence-based Practice in Athletic Training" provided by the NATA. The state of the current educational opportunity has been called into question in recent literature. ${ }^{15-17}$ Future EBM education needs a change in focus from conceptual knowledge to clinical application. The implementation of problem-based learning may put clinicians in situations in which they are required to apply EBM strategies in order to find applicable information. Consistent utilization of EBM concepts will help improve clinician comfort with the EBM process in a controlled environment. ATs who were confident in their ability to find research applicable to their patient population had increased access to evidence-based resources more frequently. Therefore, ATs should be encouraged to seek out additional education opportunities and utilize EBM routinely in order to improve confidence levels. Also, ATs who had support from their employers had increased access evidence-based resources. In order to further encourage the usage of EBM, it is suggested that employers also be aware of the potential benefits that EBM can offer to their patient population.

In order for athletic training to progress towards an EBM profession, the barriers to the adaptation must be addressed. The result of this study suggested that the barriers to implementation may not be an absence of education or lack of evidence based resources. The major obstacle for athletic training to become an evidence-based profession is filling in the gaps between the educational setting and the clinical site. 


\section{Limitations}

The primary limitation of this study is the small sample size $(n=155)$. Industrial athletic trainers were not represented in this sample. Also, this sample only encompassed National Athletic Trainers' Association members who have agreed to participate in survey research. This participant population may have been biased towards EBM or not be a true representation of all clinically practicing ATs. The accessibility, evidence based resources, and ability to deal with clinical scenarios among non-NATA members cannot be generalized from these results. Due to the design of the survey, participants who cited sufficient access to professional literature were prompted with a follow-up question regarding what resources would be utilized. Participants who did not have sufficient access were prompted with a follow-up question regarding what barriers prohibit the participant's ability to utilize professional resources. Due to the high level of accessibility noted in this sample population, the number of individuals who filled out barrier questions was very low. If participants do not have sufficient access to a computer or internet, it is possible the participant did not receive or was unable to complete an internet survey as a result. Lastly, the generalizability of the data is a limitation. The participants selected are NATA members and at the very least have access to The Journal of Athletic Training whereas nonNATA members would not have equal access. Additional recruitment methods would have to be utilized to reach a true random sample population including non-NATA members or NATA members who opted to not receive online questionnaires.

\section{CONCLUSIONS}

Based on this information gathered through this prospective exploratory study, the majority of ATs have sufficient access to professional literature and knowledge of EBM. Despite high levels of knowledge and accessibility, EBM is not being utilized in clinical practice. It is 
unclear what obstacle is preventing ATs from implementing EBM education into clinical practice The amount of EBM training was high in this study compared to prior studies conducted by Hankemeier et al. and McCarthy et al but still require improvement for athletic training to truly adopt EBM. Further education is required to educate ATs about the importance of EBM for improving patient care and encouraging the growth of the athletic training profession.. Despite high levels of accessibility to evidence-based resources the usage of non-evidence based resources remains high among ATs in all clinical settings. Resources such as Google and internet forums are most convenient but often do not contain high levels of evidence. Athletic trainers must be cautioned when utilizing non-evidence based resources and encouraged to seek out the best possible evidence available when looking for guidance for clinical decision making. The amount of evidence-based resource utilized did fluctuate based on the topic and amount of evidence-based resources available for that topic in this study. More clinically meaningful literature is required in order to continue to encourage ATs to utilize evidence-based resources versus non-evidence based resources. This can be accomplished through NATA position statements and other pre-appraised literature.

The usage of a problem-based learning via case scenarios to assess and teach EBM could be an effective measure to determine the AT's ability to fill-in knowledge gaps between conceptual education and practical application clinically. Most of the EBM education that was viewed in this study were as a result of graduate education and professional seminars. It is important that athletic training students receive EBM teaching in undergraduate education. Postgraduate ATs must be aware of other EBM education opportunities such as online modules for EBM education. Further research needs to be conducted to determine what obstacles exist from transferring conceptual EBM to the practical application if they are not hindered by accessibility 
or lack of training. Also, additional research needs to be conducted to gain additional information for an AT's ability to critically appraise high versus low quality EBM resources. Lastly, how frequently do ATs research clinical questions and what is the success rate based on topics researched. 


\section{REFERENCES}

1. Sackett DL, Rosenberg WM, Gray JA, Haynes RB, Richardson WS. Evidence based medicine: what it is and what is isn't. Br Med J. 1996;312(7023):71-72

2. Tanjong-Ghogomu E, Tugwell P, Welch V. Evidence-based medicine and the Cochrane Collaboration. Bull Hosp Jt Dis. 2009;67(2):198-205

3. Steves R, Hootman J. Evidence-Based Medicine: what is it and how does it apply to athletic training? J Athl Train. 2004;39(1):83-87

4. Brown C, Wickline M, Ecoff, L, Glaser D. Nursing practice, knowledge, attitudes, and perceived barriers to evidence-based practice at an academic medical center. $J$ Adv Nurs. 2009;65(2):371-381

5. Jette D, Bacon K, Batty C, Carlson M, Ferland A, Hemingway R, Hill J, Ogilive L, Volk D. Evidence-based practice: beliefs, attitudes, knowledge, and behaviors, or physical therapists. Phys Ther. 2003; 83.786-805

6. National Athletic Training Education Committee. Athletic Training Education Competencies: $5^{\text {th }}$ Edition. National Athletic Training Association. 2011

7. Dawes M, Sampson U. Knowledge management in clinical practice: a systematic review of information seeking behavior in physicians. Int J Med Form. 2003;71:9-15

8. Ritchie A, Sowter B. Availability and accessibility of evidence-based information resources proved by medical libraries in Australia. Aust Health Rev. 2000;23(1):77-89

9. Morris J, Maynard V. Pilot study to test the use of a mobile device in the clinical setting to access evidence-based practice resources. Worldv Evid-Based Nu. 2010; 7(4):205-213

10. McCarthy C, Hankemeier D, Walter J, Newton E, Van Lunen B. Use of evidence-based practice among athletic training educators, clinicians, and students, part 2: attitudes, beliefs, accessibility, and barriers. J Athl Train. 2013; 48(3):405-415

11. Straus S, Richardson S, Glasziou P. Haynes B. Evidence-medicine” How to practice and teach EBM. Elsevier. 2005;3.

12. McGowan J, Grad R, Pluye P, Hannes K, Deane K, Labrecque M, Welch V, Tugwell P. Electronic retrieval of health information by healthcare providers to improve practice and patient care (Review). Cochrane Database Syst Rev. 2009;3:1-23

13. Hankemeier D, Walter J, McCarty C, Newton E, Walker S, Pribesh S, Jamali B, Manspeaker S, Van Lunen B. Evidence-based practice among athletic training educators, clinicians, and students part 1: perceived importance, knowledge, and confidence. J Athl Train. 2013;48(3):394-404 
14. Kitto S, Villaneuva E, Chesters J, Petrovic A, Waxman B, Smith J. Surgeons' attitude towards and usage of evidence-based medicine in surgical practice: a pilot study. ANZ J. Surg. 2007;77:231-236

15. Welch C, Hankemeier D, Wyant A, Hays D, Pitney W, Van Lunen B. Future directions of evidence-based practice in athletic training: perceived strategies to enchance the use of evidence-based practice. J Athl Train. 2014;49(2):234-244

16. Welch C, Van Lunen B, Hankemeier D. An evidence-based practice educational intervention for athletic trainers: a randomized controlled trial. J Athl Train. 2014;49(2):210-219

17. Welch C, Van Lunen B, Hankemeier D, Wyant A, Mutchler J, Pitney W, Hays D. Perceived outcomes of web-based modules designed to enhance athletic trainers' knowledge of evidence-based practice. J Athl Train.2014;49(2):220-233

18. Snyder A, Parsons J, Valovich Mcleod T, Curtis Bay R, Michner L, Sauers E. Using disablement models and clinical outcomes assessments to enable evidence based athletic training practice, part I: Disablement Models. J Athl Train.2008;43(4):428-436

19. Huang X, Lin J, Demner-Fushman D. Evaluation of PICO as a knowledge presentation of clinical questions. AMIA Annu Symp Proc. 2006;359-363

20. Guskiewicz K, Bruce S, Cantu R, Ferrara M, Kelly J, McCrea M, Putukian M, Valovich McLeod T. National athletic trainers' association position statement: management of sportrelated concussion. J Athl Train.2004;39(3):280-297

21. Guskiewicz K, Register-Mihalik J, McCrory P, McCrea M, Johnston K, Makdissi M, Dvorak J, Davis G, Meeuwisse W. Evidence-based approach to revising the SCAT2: introduction the SCAT3. Br J Sports Med. 2013;47:289-293

22. Barr K, Harrast M. Evidence-based treatment of foot and ankle injuries in runners. Phys Med Rehabil Clin N Am. 2005;(16):779-799

23. Kaminski T, Hertel J, Amendola N, Docherty C, Dolan M, Hopkins J. Nussbaum E, Poppy W, Richie D. J Athl Train.2013;48(4):528-545

24. Ciliska D. Educating for evidence-based practice. J Adv Nursing. 2005;21(6):345-350

25. Hoogendam A, Vries Robbe P, Overbeke J. Comparing patient characteristics, type of intervention, control, and outcome (PICO) queries with unguided searching: a randomized controlled crossover trial. J Med Lib Assoc. 2012;100(2):121-126

26. Schardt C, Adams M, Ownes T, Keitz S, Fontelo P. Utilization of PICO framework to improve searching PubMed for clinical questions. BMC Med Inform Decis Mak. 2007;7(16) 
27. Ely J, Osheroff J, Chambliss L. Answering physicians' clinical questions: obstacles and potential solutions. J Am Inform Assoc. 2005;12:217-224

28. Cheng G. A study of clinical questions posed by hospital clinicians. J Med Lib Assoc. 2004;92(4):445-458

29. Westbrook J, Coiera E, Gosling S. Do online information retrieval systems help experienced clinicians answer clinical questions? J Am Med Inform. Assoc. 2005; 12(3):315-321

30. Aslam S, Emmanuel P. Formulating a researchable question: a critical step for facilitating good clinical research. Indian J Sex Trans Dis AIDS. 2010;31(1):47-50 
APPENDICIES 


\section{APPENDIX A}

\section{THE PROBLEM}

\section{Research Question}

Evidence based medicine is the "integration of the best research evidence with clinical expertise and patient values to make clinical decisions." "The integration of EBM techniques allows clinician's to effectively ask clinical questions and find quality research regarding the effectiveness of the treatment and management of patient conditions. The hallmark sign of EBM is "critical thinking and open mindedness." 1,3 Once realizing a lack of knowledge, a development of the skills to find research that apply to the individual's case will fill in the "knowledge gaps." ${ }^{3,18}$ This process encourages clinicians to continue to seek out different treatment methods scientifically supported by literature that they may not have utilized otherwise. ${ }^{1}$ If this process does not occur patients may be denied the benefits of new and potentially beneficial therapeutic options. ${ }^{2}$ Health care has moved beyond the days of making clinical decisions in the absence of evidence or making clinical decisions based on anecdotal evidence alone. Steves et al. ${ }^{3}$ stated that "literature is constantly changing and the best method of practice may change next year." Therefore, in order to provide the highest quality care to patients it is of paramount importance that ATs become constant consumers of the literature.

Allied healthcare fields such as nursing, physical therapy, and occupational therapy have already adopted EBM into clinical practice. ${ }^{3}$ EBM was recently integrated into the $5^{\text {th }}$ edition of the National Athletic Training Education Competencies ${ }^{6}$ which stated that all undergraduate athletic training students must have an understanding of EBM concepts prior to graduating from a Commission on Accreditation of Athletic Training Education (CAATE) accredited undergraduate program. The educational competencies stress a five step approach to EBM. ${ }^{1,3,6}$ 
The effectiveness of EBM has been demonstrated in other allied healthcare professions including physical therapy and nursing. ${ }^{5,6}$ In order for Athletic Training to continue to develop and remain current among other allied healthcare professionals, it is essential EBM also be adopted. ${ }^{3,11,14,18}$ There has been resistance in the adoption of EBM in athletic training. Individuals reported in a study by Ciliska ${ }^{24}$, that EBM is only the "flavor of the month" and are hesitant to adopt it as EBM will be short lived. Other commonly stated barriers include lack of support from administration and/or mentors, lack of time, limited continuing education opportunities, and insufficient access to literature. ${ }^{11,14,}$

The ability of healthcare providers to practice EBM rests heavily on clinician's knowledge of EBM concepts and the access to evidence based resources. ${ }^{8,9}$ With increasing internet access in homes, offices, and via cell phones the amount of evidence-based resources available to clinicians has been drastically increased. ${ }^{8,9}$ The development of electronic information resources including PubMed, MEDLINE, EMBASE, and Cochrane Library of databases have allowed clinicians to access a robust source of information; ${ }^{2.3,8,9,12}$ however, without access to a computer, internet connection, or journal subscriptions the accessibility of these resources is limited amongst ATs.

Accessibility to evidence based resources is crucial to implementing evidence based resources into clinical practice. If evidence based resources are not readily available, clinicians may utilize more convenient and non-evidence based sources such as colleagues and websites. A study by Jette et al. ${ }^{6}$ found that $93 \%$ of physical therapists had access to evidence based resources including professional journals either in paper or electronic form; however, participants reported reading less than 5 articles per month despite high levels of accessibility. ${ }^{6}$ Sackett et al. ${ }^{1}$ stated that physical therapists look to non-evidence based resources such as colleagues rather than 
consult literature for information for clinical decision making. ${ }^{1}$ Similarly, it is frequently assumed that ATs have sufficient access to evidence based resources. McCarthy et al. ${ }^{11}$ stated that nearly 1209 ATs surveyed had direct access to textbooks and websites; however, access varied significantly between individuals affiliated with academia (program directors, professional educators, and post-professional students) and clinician's ability to utilize MEDLINE, CINAHL, Cochrane Library, or PubMed databases. ${ }^{11}$ More than $90 \%$ of academic ATs had access to these medical databases whereas only $66.8 \%$ of clinicians without academic affiliation have the same access. ${ }^{11}$ Thus, ATs practicing outside of the collegiate setting or without affiliations with academia may have no access or limited access to full text searchable databases such as MEDLINE, SPORTDiscus, or CINAHL. ${ }^{11,13}$ Efficient access to evidence based resources is a crucial part of appropriately implementing EBM in athletic training practice. 6,11 Therefore, ATs whom work in a private clinic, secondary school, industry, or physician's office may have decreased access to literature to provide answers to clinical questions compared to those associated with academia. ${ }^{11,13}$

As a result of a rapidly growing amount of research evidence available, clinicians are faced with the task of dealing with an overflow of information; ${ }^{8,9}$ The ability for clinicians to find and appraise EBM resources in a timely fashion is not a simple task. The ability to formulate a clinical question containing all elements of the PICO format is widely believed to be the key to efficiently finding high-quality evidence to make clinical decisions amongst large bodies of literature. ${ }^{19-21}$ A well formulated clinical research question will be the difference between obtaining only clinically relevant information and a large amount of information of little to no clinical relevancy. ${ }^{19}$ The clinical question should be able to accurately relate to the diagnosis, etiology, prognosis, treatment, and/or prevention of the pathology. ${ }^{12,25,26}$ The more focused the 
clinical question the more results will relate to an individual case. Inability to focus clinical questions will only increase the time required to answer clinical questions. ${ }^{2,12}$ Therefore, it is of paramount importance that clinician's formulate well-constructed clinical research questions using the PICO format in order to effectively navigate a constantly growing bodies of literature. $^{25,26,30}$

Current research trends in EBM literature highlight the importance of EBM as an integral component of developing the profession of Athletic Training. ${ }^{3,6}$ EBM offers ways to efficiently and critically analyze constant changing research. ${ }^{3}$ Hankemeier et al. ${ }^{13}$ conducted a study, assessing the knowledge of evidenced based concepts for clinical practical assessment. Athletic trainers scored an average of $64.2 \%$ in knowledge on this topic. In the same study, Hankemeier et al. ${ }^{14}$ found that all ATs surveyed, believe that EBM was at least moderately to extremely important in clinical practice. Despite a strong perceived importance of EBM concepts, the knowledge of EBM remains low among ATs. The knowledge of this concept in ATs must improve if EBM is going to extend from academia to clinical practice. McCarthy et al. ${ }^{10}$ conducted a survey regarding attitudes and beliefs of EBP among ATs. McCarthy et al. ${ }^{10}$ found that $84.8 \%$ of participants felt the need to increase the use of evidence in daily practice. ${ }^{11}$ Based on the information gathered by McCarthy et al. ${ }^{11}$ and Hankemeier et al., ${ }^{13}$ ATs agree that EBM concepts are important and should be utilized more in clinical practice. The hesitation to implement EBM is not isolated to just athletic training, but physical therapy and nursing have experienced similar resistance as well. ${ }^{4-6}$

Athletic trainers must seek out evidence based resources in order to improve clinical outcomes. ${ }^{4}$ Healthcare has surpassed the times of making clinical decisions based on what was traditional done or what outdated research suggests. ${ }^{1,12}$ In order to provide the highest quality 
care for patients, ATs must adopt EBM concepts. It is unclear why ATs are still not utilizing EBM concepts in clinical practice. It is important to determine whether these individuals are not utilizing EBM in clinical practice due to lack of accessibility to evidence based resources such as MEDLINE, PubMed, CINAHL, Cochrane Library, or lack of training in EBM concepts to effectively apply the concepts into clinical practice. ${ }^{10,14}$ Athletic trainers must have adequate accessibility to evidence based resources to be able to utilize current evidence in clinical practice.

Therefore, the following research questions are being asked:

1. Are athletic trainers making clinical decisions based on evidence based sources (databases, textbooks, and seminars) or non-evidence based resources (colleagues, anecdotal evidence, patient preference, and clinical expertise)?

2. Are athletic trainers who have experience utilizing evidence based medicine concepts more likely to use background (disease oriented) questions or foreground (patient oriented) questions?

3. What barriers (internet access, no journal subscription, or no formal training) to accessibility prevent athletic trainers from utilizing evidence based resources versus nonevidence based resources.

4. Do athletic trainers in different clinical settings (secondary school, collegiate, industrial, professional, and clinical) have variable access to current clinical information?

Experimental Hypothesis

1. There will be a difference between collegiate athletic trainers and secondary school athletic trainers' access to current relevant research. (computer, internet access, and journal subscriptions)

2. There will be a difference between non-traditional athletic trainers (physician extender and industrial setting) and traditional athletic trainers (secondary school and collegiate) access to current relevant research. (computer, internet access, and journal subscription)

3. There will be a difference in the usage of non-evidence based resources (colleagues, anecdotal evidence, or internet forms) compared to evidence based resources (PubMed, Cochrane, PEDro) in collegiate athletic trainers compared to secondary school athletic trainers. 
4. There will be a difference in the usage of foreground compared to background questions in collegiate compared to secondary school athletic trainers when researching information related to a clinical question.

5. There will be a difference in the usage of foreground compared to background questions in athletic trainers whom have received formal training in PICO and those who have not.

6. There will be a difference in the usage of foreground compared to background questions in athletic trainers whom have support from the athletic trainer's employment site and those who do not.

7. There will be a difference in ranked importance of evidence based medicine factors (clinician expertise, patient preference, and current research) between collegiate athletic trainers and secondary school athletic trainers.

8. There will be a difference in ranked importance of evidence based medicine factors (clinician expertise, patient preference, and current research) between athletic trainers whom have received formal training in PICO and those who have not.

Assumptions

1. Participants will answer the scenarios honestly and to the best of their ability.

2. The questionnaire being used is valid and reliable.

3. Participants will return the survey completed in its entirety.

4. Participants will have knowledge of EBM.

Delimitations

1. This study drew a random sample of athletic trainers from the NATA Research Survey Service and cannot be generalized beyond the athletic training population.

2. The results of this study cannot be generalized to athletic trainers that are non-NATA members.

\section{Operational Definitions}

1. Allied Health Search Engines - A method of searching for scholarly journal articles from health care practitioners with formal education and clinical training. Allied health professionals include athletic trainers, occupational therapists, physical therapists, and nursing professionals.

2. Background Question - Disease-oriented questions referring to what, when, how, and where about the disease, disorder, or treatments. ${ }^{13,22}$ 
3. Clinical Expertise - The proficiency and judgment that clinicians acquire through clinical experience and clinical practice. ${ }^{1,13}$

4. Evidence Based Medicine - Using the most current and best available evidence in collaboration with clinical expertise and patient preferences in order to make decisions about the treatment of individual patients.

5. Evidence Based Resource - Information obtained from a textbooks, scholarly journal articles, databases, professional seminars, or curriculum education.

6. Foreground Question - Patient-oriented questions that involve the risk vs. benefit of a therapy or disease for a patient or group of patients. ${ }^{13,30}$

7. Medical Health Search Engines - a method of searching for scholarly articles from physicians with medical degrees and clinical experience.

8. Non-Evidence Based Resource - Information obtained from anecdotal evidence, colleague recommendation, or non-scholarly publications such as internet forums.

9. PICO Framework - Patient, Intervention, Comparison, Outcomes is a framework used by clinicians to articulate an effective clinical question to yield information most applicable to the clinician's patient population.$^{26}$

10. Relevant Research - Literature that provides answer or solutions to a specific patient population defined through the research question. ${ }^{26}$

11. Direct Access - The ability to access the resource and its content through work or home without the assistance of others. ${ }^{11}$

\section{Limitations}

1. Only using certified athletic trainers that are NATA members.

2. The questionnaire used is not a validated questionnaire.

3. The participants may have a biased opinion of EBM.

4. The questions on the questionnaire may be misunderstood.

5. The participants will not be in a controlled setting and may be distracted by noise.

6. The hectic environment of an athletic training facility may hinder the ability of participants to complete this survey. 
7. The participants provide the most socially favorable answers rather than answering truthfully about their clinical practice.

Significance of the Study

Evidence Based Medicine is an "integration of the best research evidence with clinical expertise and patient values to make clinical decisions." "1 Utilization of EBM framework is essential to providing the highest quality medical care to patients. If the clinician has not kept up to date on all the possible therapeutic options for a patient, they may be denied a potentially beneficial treatment option. In order to continue developing as a profession and gain increased respect from other allied healthcare providers, EBM needs to continue to develop in the field of athletic training ${ }^{3}$ EBM will help validate the effectiveness of athletic training methods objectively and further demonstrate the benefits of the athletic training profession to patients. Despite growing amounts of research in the field of athletic training validating the usage of EBM concepts in athletic training, clinicians are not utilizing EBM in clinical practice. Further research is required to determine whether EBM is not being fully adopted in the athletic training profession due to a lack of clinician ability or lack of accessibility to the necessary evidence based content at the clinical site required.

Therefore, further information needs to be conducted to determine whether knowledge of EBM is lacking to effectively apply concepts is preventing the application of EBM concepts. The information gained in this study is applicable to both practicing ATs and athletic training educators. If limitations in accessibility are preventing ATs from effectively practicing evidence based practice, additional evidence-based resources need to be made available to these clinicians. This will also serve as a foundation to advocate for the necessary resources if restrictions are present. If limitations in the knowledge of EBM are restricting ATs from effectively implementing evidence into clinical practice, increased education is required through continue 
education opportunities and in undergraduate education. This information once available will be distributed to ATs through scholarly publications, post-professional workshops, and online modules. Through these avenues of distribution, ATs will be provided with an increased understanding on the barriers that inhibit the implementation of EBM. By addressing these hurdles athletic training can move closer to fully adopting an evidence based practice culture. 


\section{APPENDIX B}

\section{REVIEW OF LITERATURE}

Introduction

Evidence Based Medicine is currently a "buzzword" in health care. ${ }^{3}$ Evidence Based Medicine or Evidence Based Practice according to Sackett ${ }^{1}$ is the "integration of the best research evidence with clinical expertise and patient values to make clinical decisions." The primary purpose of utilizing EBM in healthcare is to provide the highest quality care to patients by seeking out patient centered clinically relevant research. ${ }^{1,3,6,13,31}$ In the book Evidence Based Medicine by Straus ${ }^{11}$, it is stated that one probably would not want to have an illness or injury treated today based on the teachings that were received ten years ago. However, this still occurs. Healthcare providers including ATs have a tendency to base treatments on non-evidence based resources such as anecdotal evidence, outdated evidence, or advice from a colleague. ${ }^{6,31}$ This mindset to clinical practice denies the patient potentially new and beneficial treatments strategies. ${ }^{2}$ In order for athletic training to continue to develop and keep pace with other allied health-care professions EBM must be adopted. ${ }^{6,31}$ This literature review will examine the EBM concepts, developing a clinical research question, current state of EBM education, accessibility, and barriers to EBM.

\section{Evidence Based Medicine Concepts}

Evidence based medicine is a diligent commitment to be a constant consumer of the literature in order to provide the highest quality care to patients. ${ }^{1}$ Evidence based medicine seeks to turn a clinical problem or "knowledge gap" into an answerable clinical question. "1,2 Although, EBM should not be mistaken for a "blue-print" or "cookbook" for clinical practice. ${ }^{4}$ EBM is a three prong approach to clinical practice. ${ }^{1,13}$ When making a clinical decision it is important to consider clinical expertise, patient preference, and the best available research evidence. ${ }^{1,13 \text {, }}$ 
Evidence based medicine can be divided into a five step process including: formulating a clinical question, searching for the best evidence, a critical appraisal of evidence, applying evidence to patients, and self-evaluation. ${ }^{13}$ These steps in combination provide the foundation to the utilization of EBM.

Table B1. Five Step Approach to Evidence Based Medicine ${ }^{32}$

1. Ask the burning clinical question in PICO format

a. Patient Population: How would I describe a group of patients similar to mine?

b. Intervention: Which main intervention, prognostic factor, or exposure am I considering?

c. Comparison: What is the main alternative to compare with the intervention

d. Outcome: What can I hope to accomplish, measure, improve, or affect?

2. Collect the best evidence

a. Cochrane Database of Systemic Reviews

b. Evidence-based clinical practice guidelines (www.guidelines.gov)

3. Critically appraise the evidence

a. What were the results of the study?

b. Are the results valid (as close to the truth as possible?)

c. Will the results help me in caring for my patients?

d. Seven levels of Hierarchy of Evidence

4. Integrate evidence, clinical expertise, and patient preferences/factors to implement a decision

5. Evaluate the outcome.

The first step and arguably the most important step is formulating a clinical question. ${ }^{33,34}$ The goal of the first step is to turn a clinical problem into an answerable question. Clinicians must have the appropriate knowledge to create effective clinical questions to avoid common pitfalls such as asking questions that are irrelevant to the patient population, questions that are too vague, asking questions incomplete questions, or asking questions that are too specific that they do not yield any results. ${ }^{35}$. The clinical question should be able to accurately articulate the diagnosis, etiology, prognosis, treatment, and/or prevention. ${ }^{2}$ The more focused the clinical question the more results will relate to an individual case. ${ }^{27}$ Inability to focus clinical questions will only increase the time required to answer clinical questions. A well-constructed clinical question should be directly relevant to the individual's problem in order to yield a relevant 
answer. ${ }^{26}$ In cases where clinicians are not aware of the best available medical care for patients, questions must be asked. ${ }^{27}$ Often the answers are available in the literature but are not sought out. $^{27}$ Thus, clinicians must critically appraise knowledge and ask questions were gaps exist. ${ }^{29}$

The second step of the EBM process is searching for the best possible evidence with the assistance of a well-constructed clinical question. Clinician's should be cautioned when using generalized search engines such as Google, Bing, or Yahoo as these resources frequently gather non-scientific and low level evidence. ${ }^{12}$ There are two primary categories of literature: primary and secondary. Primary literature is obtained through original research found from relevant journals. ${ }^{12}$ The most common search engine used in the United States to search for medical literature is MEDLINE which can be accessed through PubMed. ${ }^{12,26}$ PubMed is a free service of the National Library of Medicine and can be accessed by all healthcare providers without a subscription. Databases exist such as CINAHL and SPORTDiscus require a subscription but contain relevant information to sports medicine and athletic training specifically. ${ }^{12}$ Secondary literature or "pre-appraised literature" is systematic reviews and meta-analyses. ${ }^{2}$ Databases such as PEDro and the Cochrane Library offer access to an abundance of secondary literature. According to Tanjong et al. " "the Cochrane Library is one of the fastest and most reliable sources of the best evidence for therapy on which to base clinical decisions." ${ }^{\prime 13}$ PEDro and the Cochrane Library provide access to previously researched clinical questions as well as the answers, providing shortcuts at times to the best possible research. ${ }^{1,2}$ All systematic reviews available on the Cochrane Library are critically appraised based on truthful, discriminative and feasible. The Cochrane Library has been specifically recommended as a good source of pre-appraised literature for EBM practice. ${ }^{1,2,36}$ However, there has been criticism in recent literature regarding the quality of the systematic reviews that the Cochrane Library recommends to healthcare 
providers. In a study by El Dib et al., ${ }^{36}$ stated "the Cochrane library is depreciated for offering inconsistent evidence and few straightforward recommendations." This research raises concerns about the quality of the research that is being received as a quick reference from databases such as the Cochrane Library. ${ }^{1,2,36}$ As clinicians, it is important to be critical of pre-appraised literature for inconsistencies or conclusions based on lesser evidence.

The following step is one of the most difficult to perform and requires the most judgment. ${ }^{3}$ The third step of the EBM process is being able to critically appraise the evidence that is yielded through database searches. It is important to be aware that all research evidence is created equal. The hierarchy of evidence suggests that systematic reviews and meta-analysis of randomized clinical trials (RCT) are the highest level of evidence. ${ }^{13,32}$ In descending order of importance following a meta-analysis or systematic review of RCTs include a systematic review of at least one RCT, controlled research without randomization, research without an experiment such as a case report, and editorials of respected authorities. ${ }^{13,32}$

Table B2. The Hierarchy of Evidence ${ }^{32}$

Level I Evidence from a systematic review or meta-analysis of all randomized controlled trial (RCTs) or evidence-based clinical practice guidelines based on systematic reviews of RCTs

Level II Evidence obtained from at least one well designed RCT

Level III Evidence from a well-designed controlled trial without randomization

Level IV Evidence from a well-designed case-control or cohort story

Level V Evidence from systematic reviews of descriptive and qualitative studies

Level VI Evidence from a single descriptive or qualitative study Level VII Evidence from the opinion of authorities and/or reports of expert committees

The hierarchy of evidence is a topic of great debate. Research articles have argued that the evidence based hierarchy over values the worth of randomized control trials. ${ }^{34,37}$ RCTs are capable of answering questions regarding what intervention has is more beneficial but cannot speak to the effectiveness of meeting the needs of an individual patient scenario. ${ }^{34,37}$ This is 
attributed to the purpose of RCTs is to remove any heterogeneity and individual characteristics in order to provide the most standardized and generalizable results. ${ }^{2,8}$ Therefore, despite a wellcrafted clinical question, there will be research that does not directly apply to the clinician's patient population. ${ }^{27}$ It is the responsibility of the clinician to have the research skills to evaluate the literature for validity and usefulness. ${ }^{34}$ Some things to consider when evaluating literature include: were there clearly defined subject groups, were the subjects interventions measured in the same manner, and was any follow-up study conducted? ${ }^{4}$ It is important to be aware of factors that may depreciate the study such as bias or lack of control groups. ${ }^{12}$ The Cochrane Collaboration adopted the Grading of Recommendations Assessment Development and Evaluation (GRADE) which assigns quality from high to low based randomized trials without major limitations. ${ }^{2,12}$ Athletic trainers becoming more familiar with the factors that influence the quality of research will help to promote a greater understanding of research and the utilization of not only available research but the best available research. ${ }^{2,3}$

Table B3. Grade Approach for Grading Quality of Evidence ${ }^{2}$

\begin{tabular}{|c|c|}
\hline \multicolumn{2}{|c|}{ Factors That Can Reduce the Quality of the Evidence } \\
\hline Factor & Factor \\
\hline Study Limitation & Down 1 or 2 levels \\
\hline Inconsistency of results & Down 1 or 2 levels \\
\hline Indirectness of evidence & Down 1 or 2 levels \\
\hline Imprecision & Down 1 or 2 levels \\
\hline Publication Bias & Down 1 or 2 levels \\
\hline \multicolumn{2}{|c|}{$\begin{array}{l}\text { Factors That Can Increase the Quality of the Evidence (If Study Meets all Previous Five } \\
\text { Factors) }\end{array}$} \\
\hline Factor & Consequence \\
\hline Large magnitude of effect & Up 1 or 2 levels \\
\hline $\begin{array}{l}\text { All plausible confounding would reduce the } \\
\text { demonstrated effect or increase the effect if } \\
\text { no effect was observed }\end{array}$ & Up 1 level \\
\hline Dose-response gradient & Up 1 level \\
\hline
\end{tabular}


The fourth step of the EBM process is to apply the research findings to the individual. Once the research is evaluated and shown to be valid and useful, the application to the patient is the next step. It is important to understand that EBM is not a "blue-print" and all patients should not be treated solely on clinical trials. ${ }^{3,13}$ It is the responsibility of the clinician to explain the positive and negative effects of the treatment options and make the appropriate decision based on the clinician expertise and the patient's values. ${ }^{1,2}$ According to Steves et al. ${ }^{3}$, "Although evidence may point to the "best way" to handle a clinical situation, it may not be ideal based on the individual case." EBM is a guide for clinical practice to assist clinician decision making but should never be the only factor.

The final step is to self-evaluate the entire practice. ${ }^{1,3,4}$ Clinicians should critically reflect on the effectiveness of the research. How long did the entire process take? Was the clinical question constructed well enough to yield a precise and efficient search results? Were the desired outcomes achieved? Are there any areas that require improvement? This type of self-reflection will not only improve EBM but improve the ways that individuals read research. ${ }^{3}$ The adoption of EBM is a lifelong commitment and through self-evaluation will only become more efficient with repetition. ${ }^{1,2,13}$

\section{Developing a Clinical Research Question}

Research questions can be classified into primary categories: foreground questions and background questions. ${ }^{26,28} \mathrm{~A}$ background question is defined as a "general question about a clinical problem or a disease." 28,30 A background question will yield information about the pathology but lends no insight to the patient. A foreground question is defined as a patient oriented question that considers the risk versus benefit for a specific patient population. ${ }^{28,30}$ Sackett $^{1}$ suggested that the proportion of foreground questions over background questions increases with the experience and responsibility of the clinician. MeSH terms should be used to 
reduce the number of relevant research articles excluded. ${ }^{18}$ The researcher needs to enter multiple synonyms and MeSH terms in each PICO category so that the search is as comprehensive as possible. ${ }^{20}$ In order to appropriately formulate a comprehensive list, a clinician requires at the very least knowledge of background information before being able to effectively proceed into asking foreground questions. ${ }^{18}$ Hoogedam et al. ${ }^{25}$ stated an increased knowledge in the subject area can potentially increase number and precision of the articles yielded by using the appropriate search terminology.

The creation of a clinical question is the first and most fundamental step in effectively practicing EBM. ${ }^{28}$ Thabane et al. ${ }^{38}$ stated "if energy or resources are being spent doing research, clinicians should be first spent on getting the research question right." The ability to create a clear and concise clinical research question will determine a clinician's ability to obtain clinically relevant information. ${ }^{12,6,38}$ However, in order to create a concise clinical question requires an in-depth knowledge about the subject being investigated. Sackett ${ }^{1}$ stated that a "research question usually contains four parts and be contained within a single sentence." Clinical research questions are a result of a clinician's critical evaluation of clinical practice and acknowledging a "knowledge gap" in one's practice. ${ }^{1,2}$ The desire to formulate a research question may arise as a result when the traditional intervention is ineffective or fails to deliver the desired outcome. ${ }^{38} \mathrm{Cheng}^{28}$ stated that "it is reasonable to hypothesize that asking a wellformed question would bring about higher satisfaction and with obtained information and higher success in problem solving."

It is widely believed that the most effective method for asking a clinically relevant question is utilizing the PICO framework. ${ }^{19,39,40}$ PICO is a four part framework including: the patient or problem, the intervention, comparison of intervention, and the clinical outcome. ${ }^{40}$ 
The "P" includes information relating to age range, sex, primary compliant, history, and patient population. ${ }^{30}$ The challenge that exists in researching a tightly restricted group of patients will inherently limit the number of potential sources. Whereas, if researching a broader subject group may yield greater amounts of information that does not necessarily generalize to the clinician's patient population. The "I" refers to the intervention and includes information related to the treatment, procedure, or diagnostic test. The "C" $\mathrm{C}$ " is a comparison of a new therapy versus a previously accepted management strategy. ${ }^{22,42}$ If there is no comparison within a research question a clinician should assess findings against a placebo. ${ }^{22,42}$ Lastly, the "O" refers to the desired outcome such a pain, increasing range of motion, or decreasing risk of injury. When determining the outcome measure for a research question it is important to insure that the outcome is easily quantifiable, valid, and reproducible. ${ }^{30,38,41}$ Examples of outcomes include pain score, length of hospital stay, and time to discharge. ${ }^{41}$ Research has shown that the PICO framework is an effective technique for improving clinician satisfaction with obtained information, specificity, and clarity of clinical questions. ${ }^{19,28}$

Thus, it is critical that practicing ATs utilize the PICO framework when researching to find the answers to clinical questions. Hoogedam et al. ${ }^{25}$ states that clinicians may not be spending enough time on their clinical inquiries. In a research study 22 physicians stated that they spent 10 minutes or less searching for answers to research questions. ${ }^{25}$ However, the PICO framework did not improve precision when clinicians were limited a five minute research. ${ }^{27,30,42}$ This study suggested that despite the shown efficiency of PICO an adequate amount of time is required in order to use the PICO framework effectively. ${ }^{25}$ 


\section{Current EBM Education}

Evidence based medicine has not previously been mandated to be included within athletic training education. Thus, many undergraduate students' motivation is minimal on the topics of research methods and statistics. Ciliska ${ }^{24}$ attributed this lack of motivation to a "notion that they will never develop a research project." Therefore, the information is not directly relevant to their function as clinical ATs. Despite this belief, EBM should not only be used for research skills for academics but should also be utilized in daily clinical practice. ${ }^{3,4}$

These traditional research and statistics courses do not directly correlate to the ability to find, appraise, or critique literature needed for evidence based decision making. However, the most recent $5^{\text {th }}$ edition National Athletic Training Association (NATA) Education Competencies explicitly stated that "evidence-based practice concepts and their application are essential to sound clinical decision-making and the critical examination of athletic training practice."7 Thus, EBM is a relatively new concept in athletic training and formal education is very limited. ${ }^{3,41}$ The amount of formal education for the general athletic training population is rather limited. This is problematic to the implantation of EBM. The knowledge of EBM has demonstrated the highest

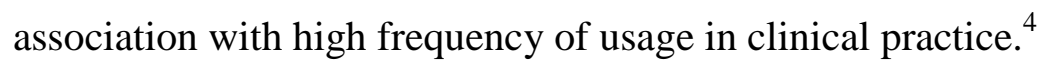

The NATA has made strides to provide post-professional seminars and modules in order to make EBM education available. ${ }^{41}$ In order to convert clinical practice to evidence based practice will require much more education for athletic training students, educators, and actively practicing ATs alike..$^{3,11,14,33}$ Individuals whom are familiar with how to perform EBM and have made evidence-based practice changes in the clinical site are required to mentor others. ${ }^{5}$ Preceptors are a critical link to encouraging the usage of EBM in young professionals. ${ }^{14}$ This may prove problematic because educators must learn this information in order to transfer this 
knowledge to the athletic training students. Educators and clinically practicing ATs will be expected to develop EBM skills and knowledge in order to comply with the most recent NATA guidelines. ${ }^{7}$ There needs to be a large commitment on the shoulders of both current athletic training student and actively practicing ATs to utilize EBP. ${ }^{33}$ This adoption of EBM among active professionals will pose as a positive example to young professionals and undergraduate students. ${ }^{14,33}$ Educators and preceptors whom have adopted evidence based practice into their personal practice are will be more willing to pass that information to students. ${ }^{14}$ Thus, students who see preceptors using the process of evidence based practice was reported as a key strategy of encouraging students to incorporate EBP into clinical practice. ${ }^{14}$ The adoption of EBM among all athletic training professionals is not an easy task. EBM is a commitment to changing in the way that ATs function clinically on a daily basis.

\section{Barriers}

Developing a deeper understanding of the barriers that hinder AT's ability to implement the best available evidence into daily practice is an important step to increasing the usage of EBM. There are two primary forms of barriers to the implementation of EBM. ${ }^{29}$ Clinician-related obstacles which are related to willingness to utilize, failure to critical evaluate daily practice, lack of understanding, lack of research skills, and a poor understanding of statistical analysis, or difficulty navigating abundant amounts of literature to obtain the required information. ${ }^{14,20,43}$ Conversely, resource-related obstacles are lack of computer access, lack of internet access, professional journal subscriptions, and insufficient time. ${ }^{6,12,43}$ Resource-related obstacles can be out of the control of the clinician. Clinician-related obstacles can be improved with a personal and diligent commitment to EBM

A barrier to EBM is an unwillingness to adopt EBM in their clinical practice. A common misconception to EBM is that it is a "cookbook" or "blue-print" to clinical practice. ${ }^{12}$ This 
misconception causes resistance among clinicians as they feel that it belittles the importance of clinical expertise. However, the best available evidence is only one of a three prong approach to making clinical decisions. Individuals whom believe that EBM restricts clinician freedom in clinical practice do not fully understand the utilization of EBM. ${ }^{1}$ The primary purpose of EBM is to improve patient care by critically evaluating clinical practice to stay abreast of new and potentially beneficial therapeutic options. ${ }^{1}$ This mindset is commonly expressed in older clinicians with many years of experience. According a systematic review by Choundrey et al., ${ }^{44}$ increased clinical experience was associated with decreased amounts of factual knowledge, decreased adherence to professional standards, and poorer patient outcomes. This is related to a higher reliance on anecdotal evidence rather than critically clinical practice and the best available evidence. ${ }^{44}$ The majority of athletic training perceptions are positive regarding the adoption of EBM. Approximately 98\% of ATs' surveyed by McCarthy et al., ${ }^{10}$ believed that EBM is beneficial for the profession and will improve patient care.

The most commonly cited barrier among ATs was lack of time to consult the literature to apply to clinical practice. ${ }^{5,11,12,14,33}$ A study by McCarthy et al. ${ }^{11}$ found that $76.6 \%$ of ATs reported insufficient time as a barrier to utilization. However, ability to formulate a clinical question containing all elements of the PICO format is widely believed to be the key to efficiently finding high-quality evidence to make clinical decisions amongst large bodies of literature. ${ }^{19}$ Also, the creation of EBM sources such as The Cochrane Library and PEDro are quick references for clinicians to access pre-appraised systematic reviews and meta-analyses. ${ }^{2,3}$ However, other research databases are not as accommodating to practicing clinicians. Databases such as PubMed do not sort search results based on relevancy. ${ }^{2,3}$ Therefore, the search results will be limited if articles do not contain all of the necessary criteria and may be lost among an 
overwhelming amount of literature. PubMed alone includes over 18 million journal citations from MEDLINE and other sources. ${ }^{2,3,34}$ This further increases the time required to identity clinically relevant information. Physicians on average only look to find answers to clinical questions very quickly searching typically for less than 10 minutes. ${ }^{18,30,42}$ More experienced clinicians demonstrated a greater efficiency in locating relevant evidence with an average search time of 6 minutes compared to 30 minutes for medical and nursing students. ${ }^{29}$ However, young professionals whom do not have a strong knowledge base in EBM will require additional time to find clinically relevant information. The clinician's knowledge of the subject matter being investigated can also influence the time required to seek out relevant research. According to Hoogendam et al., ${ }^{25}$ increased knowledge on a given subject matter can potentially increase recall based on using more adequate search terms. Without a foundation of knowledge to create appropriate MeSH terms, clinicians may have to seek out background information before seeking out foreground information..$^{20,29}$ Thus, extending the time required to find the answer to the desired clinical question.

Lack of knowledge of EBM is commonly cited barrier by ATs. ${ }^{5,11,14,19}$. There is a large disparity in knowledge of EBM among ATs in different settings. Athletic trainers associated with education typically scored higher in total knowledge scores in an assessment by Hankemeier et al. ${ }^{13}$ As well as ATs with terminal degrees had higher knowledge scores than those with bachelor's or master's degrees. ${ }^{13}$ However the average score amongst all ATs remains low at $64.2 \% .^{13}$ The adaptation of EBM is still very new in the profession of athletic training. EBM was not included into National Athletic Trainers' Association $5^{\text {th }}$ edition of the Athletic Training Educational Competencies. ${ }^{7}$ This document stated that all undergraduate athletic training students are required to complete the following competencies: define EBP as it relates to athletic 
training clinical practice, role of evidence in the clinical decision making process, differentiate between quantitative and qualitative research, levels of research, development of clinical questions, and knowledge of outcome measures. ${ }^{7}$ Athletic trainers that have graduated prior to EBM's inclusion into undergraduate education have been faced with the task of self-educating. Therefore, EBM must continue to be encouraged through continuing education opportunities. Currently, there are limitations in the education available for application of EBM into clinical practice. ${ }^{3,11}$

Another barrier is that the answers to clinical questions do not exist at this time. Research may present on a given topic but lack generalizability to the clinician's desired patient population. ${ }^{34,37}$ Increased literature that is relevant to a specific patient population is required to further improve the utilization of EBM. When the necessary research has not yet been conducted to provide answers to clinical questions, information from experts or authorities on the topic may be utilized. However, it is important to note that this is not a high level of evidence and decisions made solely based on this information should be pursued carefully. ${ }^{34,37,45}$ Accessibility

Athletic trainers are on the front lines of evidence based practice. ${ }^{13}$ Practicing clinicians are expected to utilize the best available evidence to critically evaluate clinical practice and constantly improve patient outcomes. ${ }^{13}$ However, there is limited research conducted in the area of accessibility to research-based evidence in the athletic training workforce.

In order to effectively practice EBM, it is crucial that ATs are able to access resources. ${ }^{4}$ Without the direct access to evidence-based resources, the ability of ATs to practice EBM is severely inhibited. ${ }^{5}$ Jette et al..$^{5}$ conducted a survey of physical therapists to determine the reading frequency of journals in a typical month. Jette et al. ${ }^{6}$ research demonstrated that $74 \%$ 
of respondents reported reading professional literature fewer than 5 times per month. ${ }^{6}$ According to a study by Ely et al., ${ }^{27}$ clinicians typically have between 0.7 and 18.5 questions per 10 patients they care for. Thus, a large number of clinical questions are not being pursued by clinicians. Jette et al. ${ }^{6}$ discovered that the amount of research utilized was strongly influenced by the whether the respondents had access to the internet. Respondents whom had access to the internet at home 4.7 and 2.6 times more likely at work to seek out professional literature than those without internet access. ${ }^{6}$ The use of online information retrieval system resulted in a $21 \%$ improvement in clinicians' answers to scenarios questions. ${ }^{29}$ This further supports that the usage of evidencebased resources is influenced by the availability of evidence by practicing clinicians. ATs have shown to utilize the most readily available resources rather than the most clinically relevant resource. $^{3,6,14}$

The availability of textbooks and websites are typically the most common resources among ATs. These resources are available to $98 \%$ of ATs. ${ }^{11}$ Similarly, ATs reported that textbooks and websites are the resources they are most comfortable utilizing. ${ }^{11,46}$ When seeking out the best possible evidence to answer clinical questions, textbooks and websites are not the strongest evidence based resources. It is widely believed that systematic reviews and metaanalysis are ranked higher than other studies. ${ }^{44}$ However, only $3.7 \%$ of submissions are systematic reviews. ${ }^{44}$ Textbooks can contain outdated information and may contain large amounts of information with no clinical relevance. Other commonly cited resources include colleagues, professional literature, NATA position statements, databases, and systematic or meta-analyses. ${ }^{3,11}$

Therefore, if clinicians do not have sufficient access to evidence based literature these ATs may be more willing to utilize outdated or non-evidence based resources. Based on the 
clinical setting in which an AT works strongly effects the amount and type of resources available. Sauers ${ }^{47}$ stated clinicians whom are practicing outside institutions of higher education or academic hospitals have decreased levels of accessibility to retrieve evidence to answer clinical questions. ${ }^{47}$ Even if a computer and internet access is available, clinicians with no access to full text searchable databases such as CINAHL, SPORTDiscus, or subscription-required resources will have restricted resources. This is the case for many ATs not affiliated with academia and even ATs employed at smaller liberal art institutions. ${ }^{47}$ If young ATs are "completely cut off from access to the best available evidence," it is not feasible for ATs to implement the best available evidence into clinical practice. ${ }^{47}$ Regardless of the level of EBM knowledge or willingness to improve clinical practice, the accessibility must be present in order to effectively practice EBM.

Summary

Evidence based medicine is a growing trend in healthcare. The primary goal of evidence based is to improve patient outcomes and validate the effectiveness of athletic training services. Implementing EBM encourages clinicians to critically assess daily clinical practice to improve effectiveness of athletic training services. Without the usage of EBM, patients may be denied potentially beneficial treatment options. EBM is a five step approach including developing a research question, searching the best available evidence, critically appraise, determine if applicable based on patient preference and clinician expertise, and evaluate the outcome of the intervention. The ability of a clinician to develop an effective clinical question dictates the success of the research results yielded. A well-constructed question will yield the highest number of clinically relevant evidence and limit the amount of articles with no significance. The ability of ATs to utilize evidence-based resources into clinical practice is hindered by both clinician- 
related obstacles and resource related obstacles. Clinician-related obstacles refer to willingness and knowledge of ATs to utilize research-evidence in daily practice. Conversely, resourcerelated obstacles are related to having no computer access, no internet access, and/or no subscription to scholarly publications. ATs must overcome both types of obstacles in order to perform EBM. Therefore, ATs must have the appropriate access and knowledge in order to fully adopt EBM into professional practice. 


\section{APPENDIX C}

\section{ADDITIONAL METHODS}

Table C1. Initial Cover Letter to Certified Athletic Trainers

February 7, 2014

Dear Selected Participant:

You are being sent this message as a request to participate in a research study based on your certified athletic trainer membership status with the National Athletic Trainers' Association. My name is Kenneth Faldetta and I am currently a graduate student in the West Virginia University Graduate Athletic Training program with a graduate assistantship with WVU men's soccer. I will be conducting a study with the primary investigator Michelle A. Sandrey PhD, ATC to fulfill requirements for a Master's thesis and to complete an MS degree in Athletic Training. All are affiliated with West Virginia University.

The following survey includes between 34 and 42 items which is variable based on specific answers to certain questions. Questions include multiple choice, ranking, single answer, and scenario questions assessing the usage of evidence based resources and the knowledge of evidence based medicine. You are not required to answer all of the questions and you are permitted to withdraw from this study at anytime without consequence. The survey should take approximately 15 minutes to complete. Please click the following link to complete the survey. (https://www.surveymonkey.com/s/9DQ2F5D)

Your involvement in this survey will be kept completely anonymous throughout the entire study. You will not be required to include your name or any other information that may potentially jeopardize the anonymity of the participants. Your job status will not be affected by failure to participate. West Virginia IRB has approved this study and approval is on file. You may withdraw from the study at any time.

I would like to respectfully request that you participate in this study, as it may provide a further understanding to the usage of evidence based medicine resources and knowledge that exist among practicing athletic trainers in using evidence based medicine. Thank you so much for your time. If you have any questions or concerns please contact me at 304-293-9868 or by email at Ken.Faldetta@mail.wvu.edu. You may also contact Dr. Michelle Sandrey, Principal Investigator and Graduate Athletic Training Program Director at West Virginia University, at (304) 293-0870 or at msandrey@ mail.wvu.edu.

Thank you in advance for your participation in this study.

Sincerely,

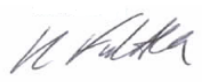

Kenneth G. Faldetta, ATC 
1. Please specify your gender
a. Male
b. Female

2. Please select the response that best corresponds to your age group
a. $20-29$
b. $30-39$
c. $40-49$
d. $50+$

3. Please specify in what athletic training setting you currently are employed
a. Collegiate
b. High School
c. Industrial
d. Clinical
e. Other, Please specify

4. How long have you been BOC certified?
a. $0-5$ years
b. 6-10 years
c. $10-15$ years
d. 15-20 years
e. $21+$ years

5. How long have you been serving as an athletic trainer at your current clinical site?
a. $0-5$ years
b. 6-10 years
c. 11-15 years
d. 16-20 years
e. $21+$ years

6. Do you have access to current research through professional journals? (If no, skip to Question 8)
a. Yes
b. No

7. What type of access to you have to professional journals?
a. Electronic Access
b. Paper Access
c. Other

8. Do you have access to applicable databases and internet at your facility? (If yes, skip to Question 10)
a. Yes
b. No

9. What barrier(s) prevent you from utilizing the internet and/or applicable databases at your facility?
a. No Computer
b. No Internet Access
c. Other

10. Are you familiar with utilizing medical and allied health search databases (PubMed, MEDLINE, SPORTDiscus, Cochrane Library)
a. Yes
b. No 
11. Are you confident in your ability to find applicable research specific to your patient population?
a. Strongly Agree
b. Agree
c. Neutral
d. Disagree
e. Strongly Disagree

12. My employment setting supports the use of current research in my clinical practice
a. Strongly Agree
b. Agree
c. Neutral
d. Disagree
e. Strongly Disagree

13. Do you have any prior education in Evidence Based Medicine? (If no, skip to Question 15)
a. Yes
b. No

14. If you have received prior education in Evidence Based Medicine, where did you receive your education? (Select all that apply)
a. Undergraduate Education
b. Graduate Education
c. Professional Seminars
d. Online Modules
e. Other

15. Do you have any formal training in the Patient, Intervention, Comparison, Outcome (PICO) framework finding research relevant to your practice? (If no, skip to Question 17)
a. Yes
b. No

16. If you have received prior education in the Patient, Intervention, Comparison, Outcome (PICO) framework, where did you receive your education? (Select all that apply)
a. Undergraduate Education
b. Graduate Education
c. Professional Seminars
d. Online Modules
e. Other

17. Please rank the following factors from most important to least important in making a clinical decision? (1 Most Important - 3 Least Important)
Patient Preference
Clinician Expertise
Current Research 
Case Study 1: 13 year old male patient presents with concerns for chronic heel pain. Athletic trainer suspects that patient may have possible Sever's disease. He stated that he has been receiving ice massage only. What other modalities can be utilized for this patient for pain control?

18. What resources would you utilize to provide the necessary information to treat this athlete? (Select all that apply)
a. Colleagues
b. Internet Database
c. Journal Articles
d. Seminars
e. Textbook
f. Anecdotal Evidence
g. Other

19. What keywords would you use to find applicable information regarding Sever's Disease?
a. Adolescent, Male, Sever's Disease, Modalities, Pain
b. Sever's disease
c. Male and Chronic Heel pain
d. Chronic Heel Pain, Adolescent, Treatment
e. Other

20. Do you have access to research that is applicable to your patient population at your clinical site to help guide clinical decision making? If no, please explain? (If yes, skip to Question 22)
a. Yes
b. No

21. If you do not have access to research that is applicable to your patient population at your clinical site. What barriers prevent your access? (Any answer, skip to Question 23)
a. No internet access
b. No subscription to medical or allied health journals
c. No computer access
c. Other

22. What kind of internet resources would you utilize to find applicable information pertaining to your clinical research question? (Select all that apply)
a. Google
b. Ebsco Host
c. Pubmed
d. Internet Forums
e. Other Internet Resources
f. No Internet Access

Case Study 2: 18 year old football athlete presented with a possible concussion. Athlete reported having symptoms for the past three days including headache, nausea, and light sensitivity. What neurocognitive assessment tools are effective in assessing concussions?

23. What resources would you utilize to provide the necessary information to treat this athlete? (Select all that apply)
a. Colleagues
b. Internet Database
c. Journal Articles
d. Seminars
e. Textbook
f. Anecdotal Evidence
g. Other 
24. What keywords would you use to find applicable information regarding neurocognitive assessment tools?

a. Male, Concussion, Assessment, Neurocognitive

b Concussion

c. Male and Concussion

d. Concussion, Adult, Assessment

25. Do you have access to research that is applicable to your patient population at your clinical site to help guide clinical decision making? (If yes, skip to Question 27)
a. Yes
b. No

26. If you do not have access to research that is applicable to your patient population at your clinical site. What barriers prevent your access? (Any answer, skip to Question 28)
a. No internet access
b. No subscription to medical or allied health journals
c. No computer access
c. Other

27. What kind of internet resources would you utilize to find applicable information pertaining to your clinical research question? (Select all that apply)
a. Google
b. Ebsco Host
c. Cochrane Database
d. Pubmed
e. Internet Forums
f. Other Internet Resources

Case Study 3: 16 year old female swimming athlete presents with concerns for asthma. Athlete is currently utilizing an albuterol inhaler but is interested in long-term control medication. Are there medications this athlete can utilize with her albuterol inhaler?

28. What resources would you utilize to provide the necessary information to treat this athlete? (Select all that apply)
a. Colleagues
b. Internet Database
c. Journal Articles
d. Seminars
e. Textbook
f. Anecdotal Evidence

29. What keywords would you use to find applicable information regarding this long-term control medication?
a. Adolescent, Asthma, Medication, Long-term Control
b. Asthma
c. Female and Asthma
d. Asthma, Adolescent, Medication

30. Do you have access to research that is applicable to your patient population at your clinical site to help guide clinical decision making? (If yes, skip to Question 32)
a. Yes
b. No 
31. If you do not have access to research that is applicable to your patient population at your clinical site. What barriers prevent your access? (Any answer, skip to Question 34)
a. No internet access
b. No subscription to medical or allied health journals
c. No computer access
c. Other

32. What kind of internet resources would you utilize to find applicable information pertaining to your clinical research question? (Select all that apply)
a. Google
b. Ebsco Host
c. Pubmed
d. Internet Forums
e. Other Internet Resources

Case Study 4: 19 year old collegiate baseball player presents with wrist pain. The athletic trainer suspects that the athlete may have a TFCC tear. What diagnostic imaging technique is currently the gold standard for diagnosing TFCC lesions?

33. What resources would you utilize to provide the necessary information to treat this athlete? (Select all that apply)
a. Colleagues
b. Internet Database
c. Journal Articles
d. Seminars
e. Textbook
f. Anecdotal Evidence

34. What keywords would you use to help in your research to find applicable information to find relevant information regarding this topic?
a. Adult, Wrist Pain, Diagnostic Imaging, TFCC
b. TFCC Injury
c. Male and Wrist Pain
d. Wrist Pain, Adult, Diagnostic Imaging

35. Do you have access to research that is applicable to your patient population at your clinical site to help guide clinical decision making? (If yes, skip to Question 37)
a. Yes
b. No

36. If you do not have access to research that is applicable to your patient population at your clinical site. What barriers prevent your access? (Any answer, skip to Question 38)
a. No internet access
b. No subscription to medical or allied health journals
c. No computer access
c. Other

37. What kind of internet resources would you utilize to find applicable information pertaining to your clinical research question? (Select all that apply)
a. Google
b. Ebsco Host
c. Pubmed
d. Internet Forums
e. Other Internet Resources 
Case Study 5: 20 year old male soccer athlete presents with chronic ankle instability. What rehabilitation exercises can be utilized to prevent the occurrence of lateral ankle sprains?

38. What resources would you utilize to provide the necessary information to treat this athlete? (Select all that apply)
a. Colleagues
b. Internet Database
c. Journal Articles
d. Seminars
e. Textbook
f. Anecdotal Evidence

39. What keywords would you utilize to find the necessary information to treat this athlete?
a.
b.

c.

40. Do you have access to research that is applicable to your patient population at your clinical site to help guide clinical decision making? (If yes, skip to Question 42)
a. Yes
b. No

41. If you do not have access to research that is applicable to your patient population at your clinical site. What barriers prevent your access? (Any answer, end survey)
a. No internet access
b. No subscription to medical or allied health journals
c. No computer access
c. Other

42. What kind of internet resources would you utilize to find applicable information pertaining to your clinical research question? (Select all that apply)
a. Google
b. Ebsco Host
c. Pubmed
d. Internet Forums
e. Other Internet Resources 
February 21, 2014

Dear Selected Participant:

You are being sent this message as a request to participate in a research study based on your certified athletic trainer membership status with the National Athletic Trainers' Association. My name is Kenneth Faldetta and I am currently a graduate student in the West Virginia University Graduate Athletic Training program with a graduate assistantship with WVU men's soccer. I will be conducting a study with the primary investigator Michelle A. Sandrey PhD, ATC to fulfill requirements for a Master's thesis and to complete an MS degree in Athletic Training. All are affiliated with West Virginia University.

The following survey includes between 34 and 42 items which is variable based on specific answers to certain questions. Questions include multiple choice, ranking, single answer, and scenario questions assessing the usage of evidence based resources and the knowledge of evidence based medicine. You are not required to answer all of the questions and you are permitted to withdraw from this study at anytime without consequence. The survey should take approximately 15 minutes to complete. Please click the following link to complete the survey. (https://www.surveymonkey.com/s/9DQ2F5D)

Your involvement in this survey will be kept completely anonymous throughout the entire study. You will not be required to include your name or any other information that may potentially jeopardize the anonymity of the participants. Your job status will not be affected by failure to participate. West Virginia University IRB has approved this study and approval is on file. You may withdraw from the study at any time.

I would like to respectfully request that you participate in this study, as it may provide a further understanding to the usage of evidence based medicine resources and knowledge that exist among practicing athletic trainers in using evidence based medicine. Thank you so much for your time. If you have any questions or concerns please contact me at 304-293-9868 or by email at Ken.Faldetta@mail.wvu.edu. You may also contact Dr. Michelle Sandrey, Principal Investigator and Graduate Athletic Training Program Director at West Virginia University, at (304) 293-0870 or at msandrey@ mail.wvu.edu. This is follow-up e-mail to let you know there is still time to participate in this survey.

Thank you in advance for your participation in this study. Sincerely,

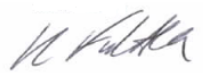

Kenneth G. Faldetta, ATC 


\section{APPENDIX D}

\section{ADDITIONAL RESULTS}

Table D1. Demographic Information

\begin{tabular}{|c|c|c|}
\hline Characteristic & Percent & $\mathrm{N}=155$ \\
\hline \multicolumn{3}{|l|}{ Age } \\
\hline $20-29$ & $26.45 \%$ & 41 \\
\hline $30-39$ & $29.03 \%$ & 45 \\
\hline $40-49$ & $27.10 \%$ & 42 \\
\hline $50+$ & $17.42 \%$ & 27 \\
\hline \multicolumn{3}{|l|}{ Employment Setting } \\
\hline Clinical & $11.0 \%$ & 17 \\
\hline Collegiate & $38.7 \%$ & 60 \\
\hline High School & $35.5 \%$ & 55 \\
\hline Industrial & $0 \%$ & 0 \\
\hline \multicolumn{3}{|c|}{ Years of BOC Certification } \\
\hline $0-5$ & $23.9 \%$ & 37 \\
\hline $6-10$ & $15.5 \%$ & 24 \\
\hline $11-15$ & $17.4 \%$ & 27 \\
\hline $16-20$ & $16.1 \%$ & 25 \\
\hline $21+$ & $25.8 \%$ & 40 \\
\hline \multicolumn{3}{|c|}{ Years of at Employment Setting } \\
\hline $0-5$ & $49.02 \%$ & 75 \\
\hline $6-10$ & $15.69 \%$ & 24 \\
\hline $11-15$ & $13.07 \%$ & 20 \\
\hline $16-20$ & $7.19 \%$ & 11 \\
\hline $21+$ & $15.03 \%$ & 23 \\
\hline
\end{tabular}


Table D2. EBM and PICO Training

\begin{tabular}{lll}
\hline Characteristic & Percent & $\mathrm{N}=155$ \\
\hline EBM Training & & \\
Undergraduate Education & $40.00 \%$ & 34 \\
Graduate Education & $55.29 \%$ & 47 \\
Professional Seminars & $57.65 \%$ & 49 \\
Online Modules & $22.35 \%$ & 19 \\
$\quad$ Other & $3.53 \%$ & 3 \\
PICO Training & $10.00 \%$ & 3 \\
$\quad$ Undergraduate Education & $50.00 \%$ & 15 \\
Graduate Education & $50.00 \%$ & 15 \\
Professional Seminars & $33.33 \%$ & 10 \\
Online Modules & $10.00 \%$ & 3 \\
Other & &
\end{tabular}

Table D3. Accessibility and Knowledge

\begin{tabular}{lll}
\hline Characteristics & Percent & $\mathrm{N}=155$ \\
\hline Access to Professional Journals & & \\
Yes & $96.77 \%$ & 150 \\
Electronic Access & $92.52 \%$ & 105 \\
Paper Access & $71.43 \%$ & 1 \\
Other & $0.68 \%$ & 5 \\
No & $3.23 \%$ & 5 \\
Access to Internet/Internet Database & & \\
Yes & $82.78 \%$ & 125 \\
No No Computer & $17.22 \%$ & 26 \\
$\quad 11.1 \%$ & 1 \\
$\quad$ No Internet & $11.1 \%$ & 1 \\
Other & $88.9 \%$ & 8 \\
Familiarity with Medical/Allied Health Database & & 76 \\
Yes No & $49.03 \%$ & 79 \\
No & $50.97 \%$ & 88 \\
EBM Training & & 61 \\
Yes No & $59.06 \%$ & 32 \\
PICO Training & $40.94 \%$ & 114 \\
Yes & & \\
No & $21.92 \%$ & \\
\hline
\end{tabular}


Table D4. Most Important EBM Component

\begin{tabular}{lll}
\hline Component & Percent & $\mathrm{n}$ \\
\hline Clinical Expertise & $58.7 \%$ & 84 \\
Patient Preference & $16.8 \%$ & 24 \\
Current Research & $24.5 \%$ & 35 \\
\hline
\end{tabular}

Table D5. Resources Utilized

\begin{tabular}{lllllllllll}
\hline Resource & \multicolumn{3}{c}{ Scenario 1 } & \multicolumn{2}{c}{ Scenario 2 } & \multicolumn{2}{c}{ Scenario 3 } & \multicolumn{2}{c}{ Scenario 4 } & \multicolumn{2}{c}{ Scenario 5 } \\
\hline & $\%$ & $\mathrm{n}$ & $\%$ & $\mathrm{n}$ & $\%$ & $\mathrm{n}$ & $\%$ & $\mathrm{n}$ & $\%$ & $\mathrm{n}$ \\
\hline Colleagues & $23.8 \%$ & 116 & $23.1 \%$ & 101 & $23.6 \%$ & 92 & $24.4 \%$ & 94 & $21.9 \%$ & 95 \\
Internet & $20.7 \%$ & 101 & $17.8 \%$ & 78 & $22.6 \%$ & 88 & $21.2 \%$ & 82 & $16.9 \%$ & 73 \\
Database & & & & & & & & & & \\
Journal Articles & $19.5 \%$ & 95 & $18.9 \%$ & 83 & $18.5 \%$ & 72 & $20.5 \%$ & 79 & $21 \%$ & 91 \\
Textbooks & $18.1 \%$ & 88 & $12.1 \%$ & 53 & $12.6 \%$ & 49 & $14.0 \%$ & 54 & $15.7 \%$ & 68 \\
Seminars & $9.2 \%$ & 45 & $13.2 \%$ & 58 & $7.7 \%$ & 30 & $8.5 \%$ & 33 & $13.4 \%$ & 58 \\
Anecdotal & $6.6 \%$ & 32 & $8.4 \%$ & 37 & $6.4 \%$ & 25 & $7.0 \%$ & 27 & $8.8 \%$ & 38 \\
$\begin{array}{l}\text { Evidence } \\
\text { Other }\end{array}$ & $2.1 \%$ & 10 & $6.4 \%$ & 28 & $8.7 \%$ & 34 & $4.4 \%$ & 17 & $2.3 \%$ & 10 \\
\hline
\end{tabular}

Table D6. Internet Resources Utilized

\begin{tabular}{lllllllllll}
\hline Resource & \multicolumn{2}{c}{ Scenario 1 } & \multicolumn{2}{c}{ Scenario 2 } & \multicolumn{2}{c}{ Scenario 3 } & \multicolumn{2}{c}{ Scenario 4 } & \multicolumn{2}{c}{ Scenario 5 } \\
\hline & $\%$ & $\mathrm{n}$ & $\%$ & $\mathrm{n}$ & $\%$ & $\mathrm{n}$ & $\%$ & $\mathrm{n}$ & $\%$ & $\mathrm{n}$ \\
\hline Google & $36.2 \%$ & 102 & $32.3 \%$ & 94 & $37.5 \%$ & 93 & $37.3 \%$ & 93 & $36.8 \%$ & 93 \\
EBSCO Host & $14.9 \%$ & 42 & $13.4 \%$ & 39 & $16.1 \%$ & 40 & $16.9 \%$ & 42 & $15.4 \%$ & 39 \\
PubMed & $34.0 \%$ & 96 & $31.3 \%$ & 91 & $33.9 \%$ & 84 & $33.3 \%$ & 83 & $34.4 \%$ & 87 \\
Internet Forums & $7.1 \%$ & 20 & $7.9 \%$ & 23 & $9.7 \%$ & 24 & $8.8 \%$ & 22 & $9.9 \%$ & 25 \\
Other & $7.8 \%$ & 22 & $6.5 \%$ & 19 & $2.8 \%$ & 7 & $3.6 \%$ & 9 & $3.6 \%$ & 9 \\
\hline
\end{tabular}

Table D7. Evidence Based Resources Versus Non-Evidence Based Resources

\begin{tabular}{ll}
\hline Scenarios & \\
\hline Scenario 1 & $0.05 \pm 0.960$ \\
Scenario 2 & $0.13 \pm 0.960$ \\
Scenario 3 & $0.03 \pm 0.987$ \\
Scenario 4 & $0.03 \pm 0.983$ \\
Scenario 5 & $0.12 \pm 0.976$ \\
\hline
\end{tabular}

KEY: -1 Non Evidence Based to +1 Evidence Based Resources; PubMed, Ebsco, Cochrane $=+1$; Internet Forums and Google $=-1$; Other $=0$ 
Table D8. Chi Square Between Employment Setting and Professional Journal Subscription

\begin{tabular}{llll}
\hline Scenario & $\chi^{2}{ }_{1,155}$ & P-value & $\begin{array}{l}\text { Contingency } \\
\text { Coefficient }\end{array}$ \\
\hline Scenario 1 & 3.791 & 0.435 & 0.155 \\
Scenario 2 & 3.605 & 0.462 & 0.151 \\
Scenario 3 & 3.414 & 0.491 & 0.147 \\
Scenario 4 & 6.422 & 0.170 & 0.199 \\
Scenario 5 & 8.234 & 0.083 & 0.225 \\
\hline
\end{tabular}

KEY: * significant finding at $\mathrm{P}<.05$

Table D9. Chi Square between Employer Support and Accessibility

\begin{tabular}{llll}
\hline Resource & $\chi^{2}{ }_{1,155}$ & P-value & $\begin{array}{l}\text { Contingency } \\
\text { Coefficient }\end{array}$ \\
\hline Professional Journals & 7.803 & 0.167 & 0.219 \\
Internet/Internet Database & $98.459^{*}$ & 0.000 & 0.623 \\
\hline
\end{tabular}

KEY: * significant finding at $\mathrm{P}<.05$

Table D10. Chi Square between Confidence in Finding and Accessibility to Internet/Internet Database

\begin{tabular}{llll}
\hline Resource & $\chi^{2}{ }_{1,155}$ & P-value & $\begin{array}{l}\text { Contingency } \\
\text { Coefficient }\end{array}$ \\
\hline Internet/Internet Database & $95.863^{*}$ & 0.000 & 0.618 \\
Professional Journals & 4.198 & 0.521 & 0.162 \\
\hline
\end{tabular}

KEY: * significant finding at $\mathrm{P}<.05$ 
Figure D1. EBM Training

\section{If you have received prior education or training in Evidence Based Medicine, where did you receive your education or training? (select all that apply)}

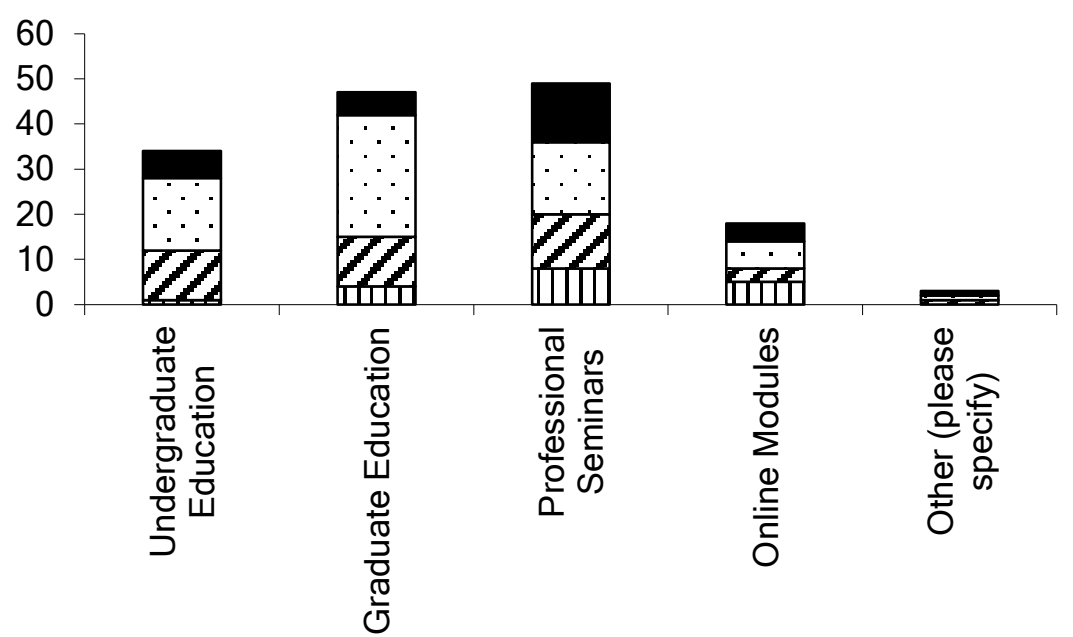

\begin{tabular}{|l}
\hline Other (please \\
specify) \\
$\square$ Collegiate \\
$\square$ High School \\
$\square$ Industrial \\
$\square$ Clinical
\end{tabular}

Figure D2. PICO Training

If you have received education or training in PICO, where did you receive your education or training? (select all that apply)

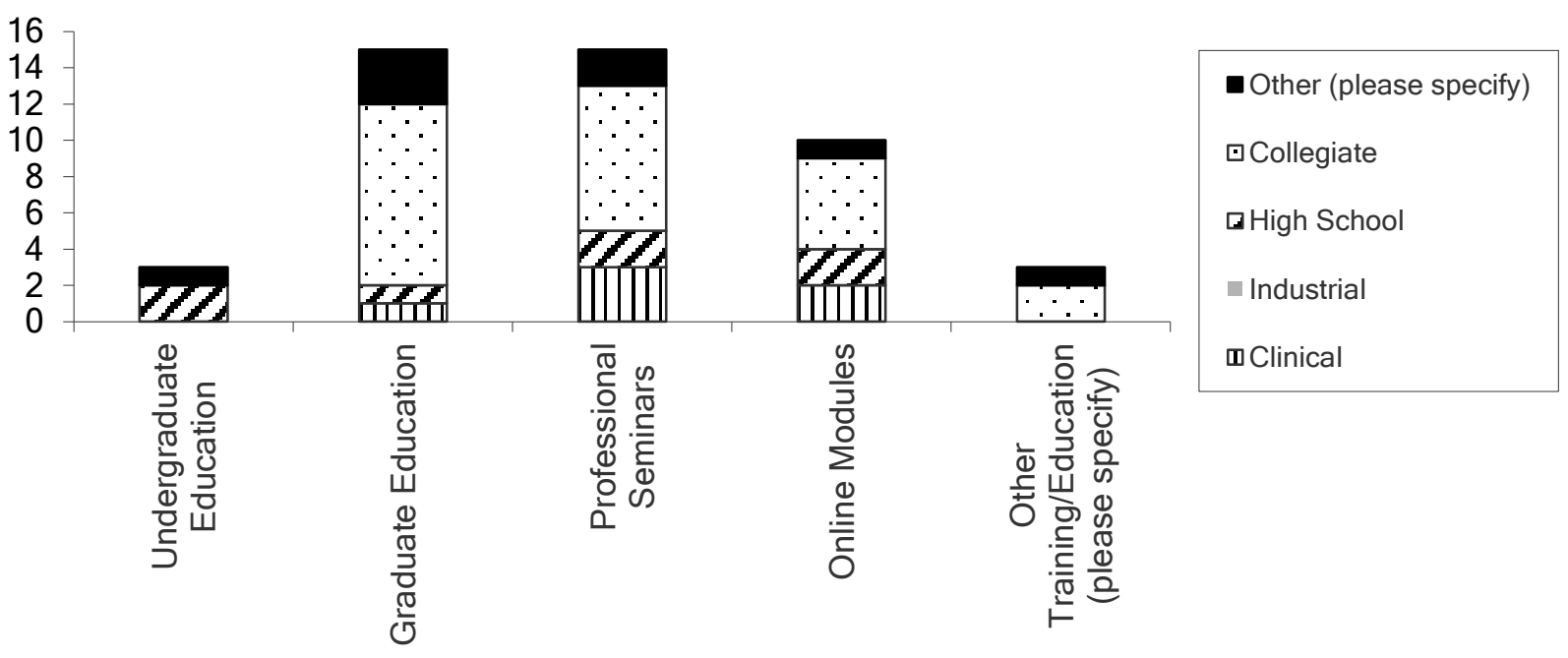


Figure D3. Resources Utilized for Scenario 1 - Sever's Disease

If you have received education or training in PICO, where did you receive your education or training? (select all that apply)

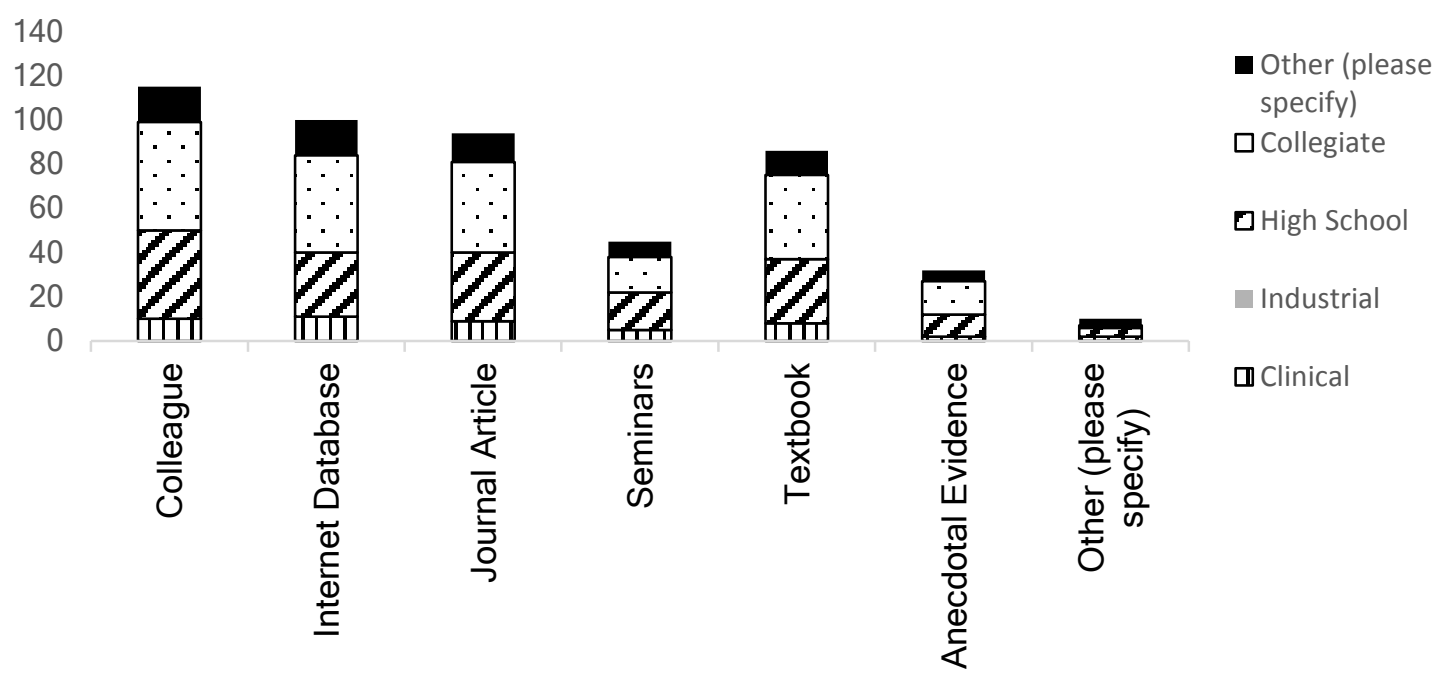

Figure D4. Internet Resources Utilized for Scenario 1 - Sever's Disease

What kind of internet resource(s) would you utilize to find applicable information pertaining to your clinical research question? (select all that apply)

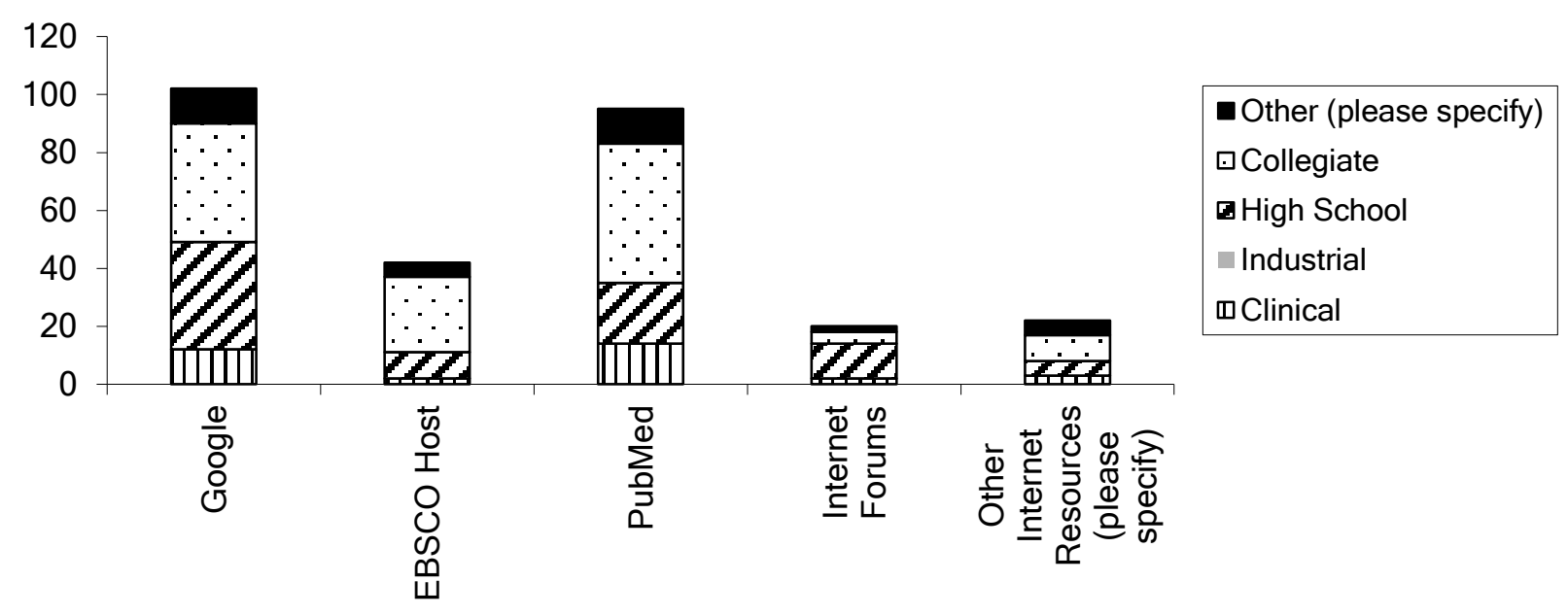


Figure D5. Resources Utilized for Scenario 2 - Concussion Assessment

What resource(s) would you utilize to obtain the necessary information to treat this
athlete? (select all that apply)

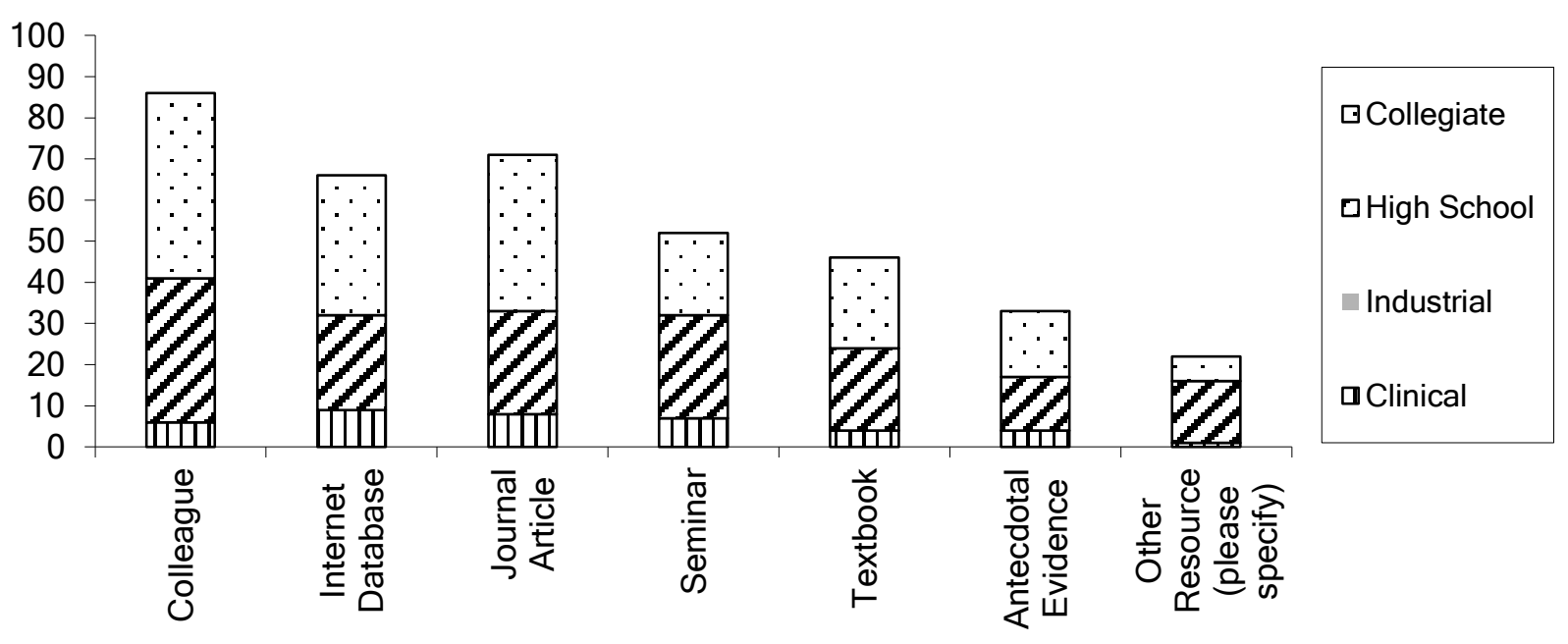

Figure D6. Internet Resources Utilized for Scenario 2 - Concussion Assessment

What kind of internet resource(s) would you utilize to find applicable information pertaining to your clinical research question? (select all that apply)

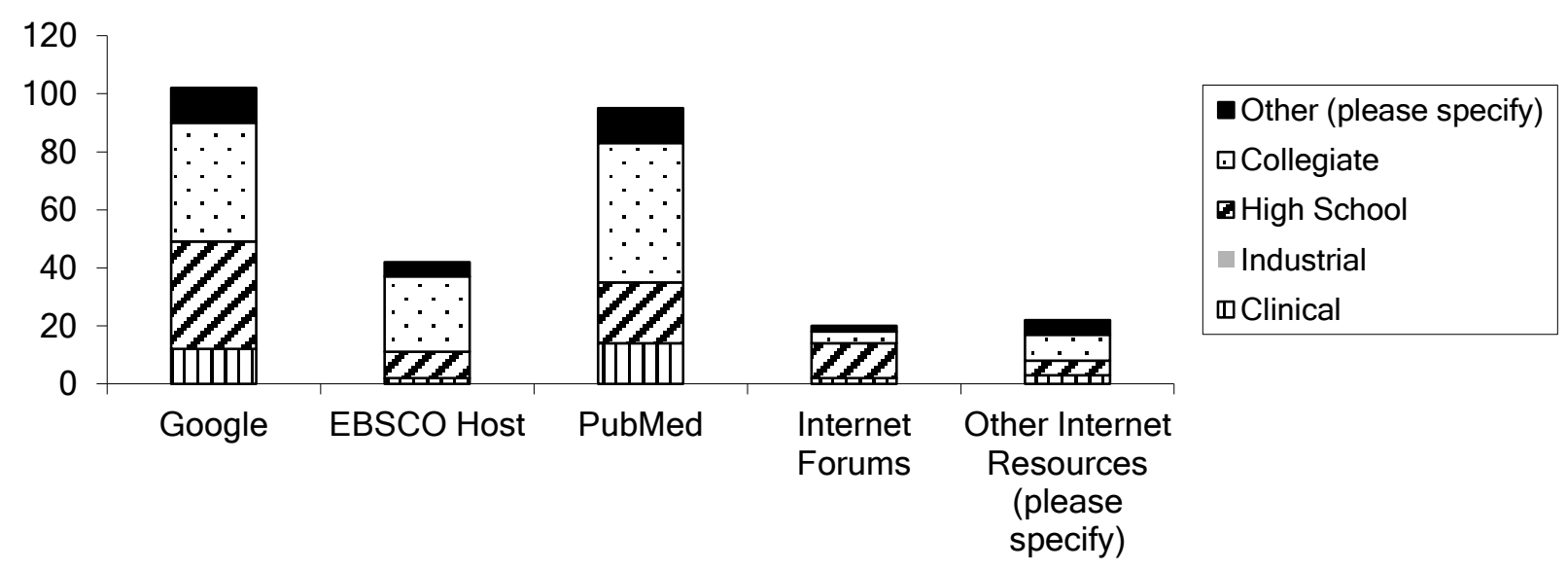


Figure D7. Resources Utilized for Scenario 3 - Asthma Medication

\section{What resource(s) would you utilize to obtain the necessary information to treat this athlete? (select all that apply)}

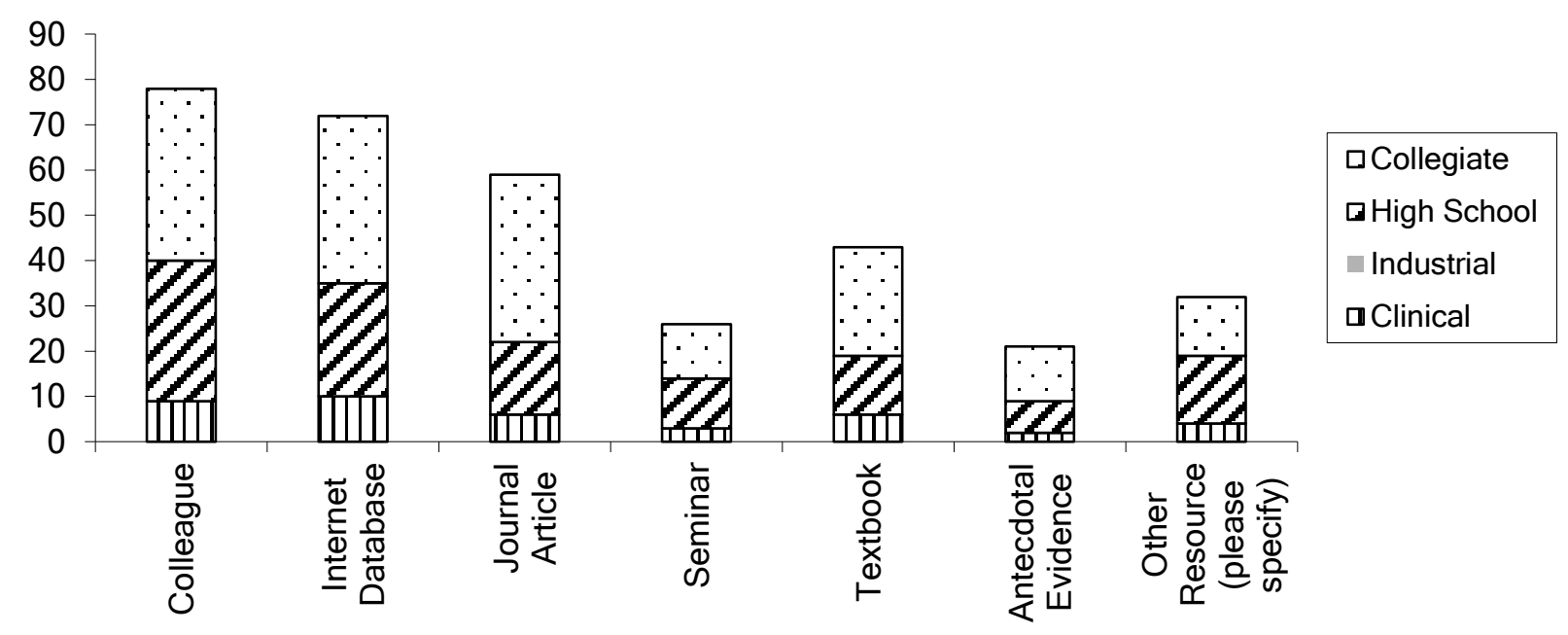

Figure D8. Internet Resources Utilized for Scenario 3 - Asthma Medication

\section{What kind of internet resource(s) would you utilize to find applicable information} pertaining to your clinical research question? (select all that apply)

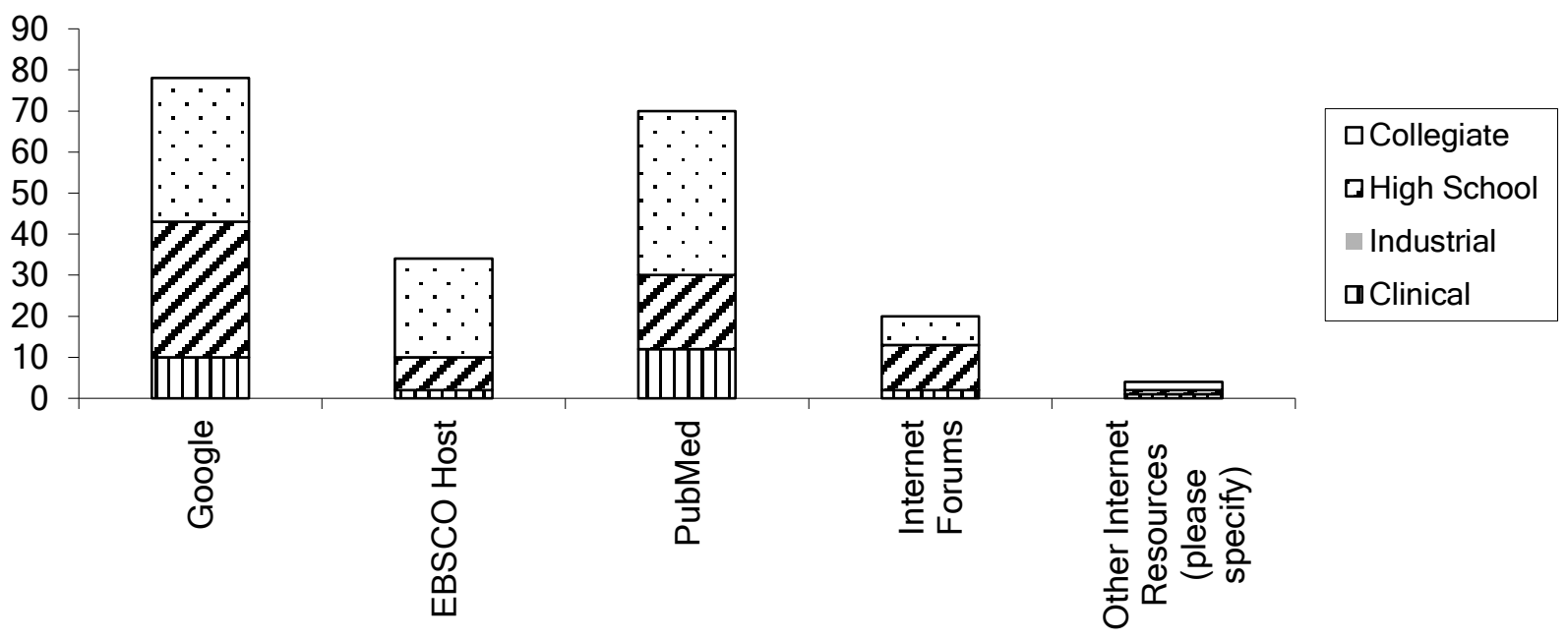


Figure D9. Resources Utilized for Scenario 4 - TFCC Diagnostic Imaging

\section{What resource(s) would you utilize to obtain the necessary information to treat this athlete? (select all that apply)}

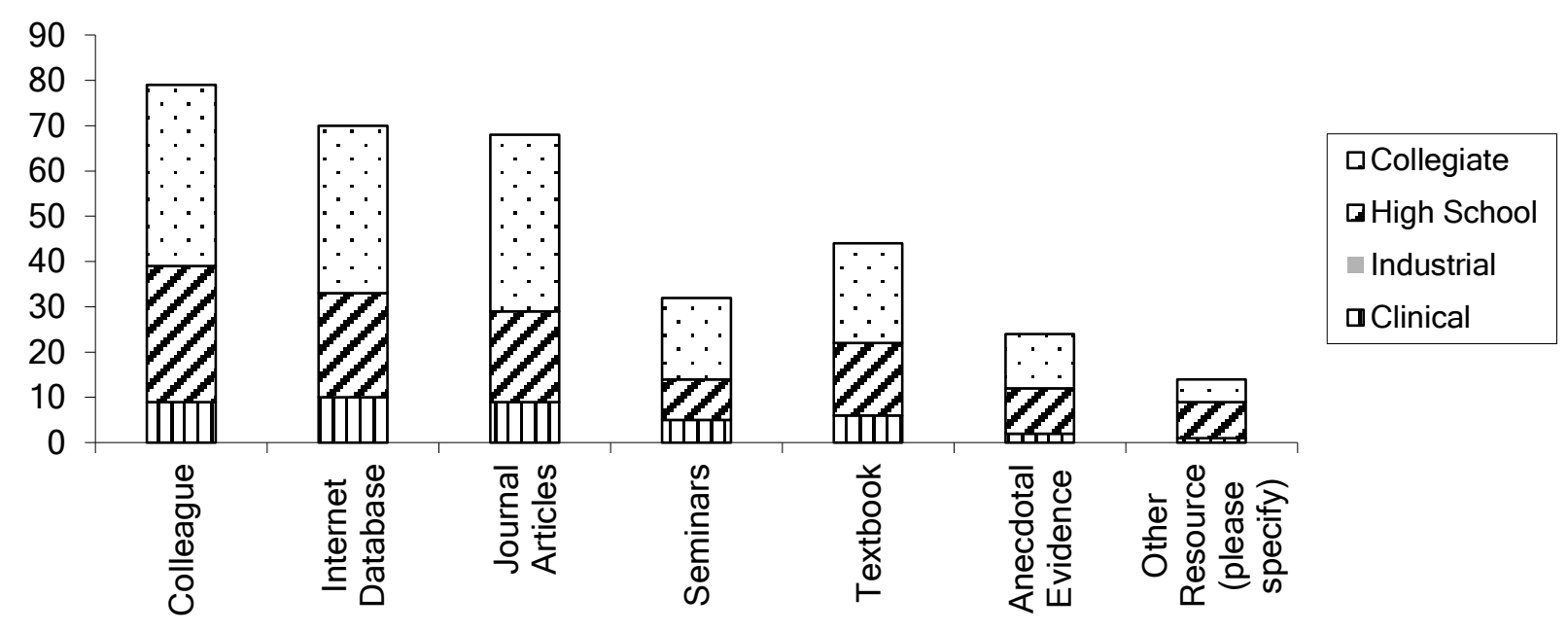

Figure D10. Internet Resources Utilized for Scenario 4 - TFCC Diagnostic Imaging

What kind of internet resource(s) would you utilize to find applicable information pertaining to your clinical research question? (select all that apply)

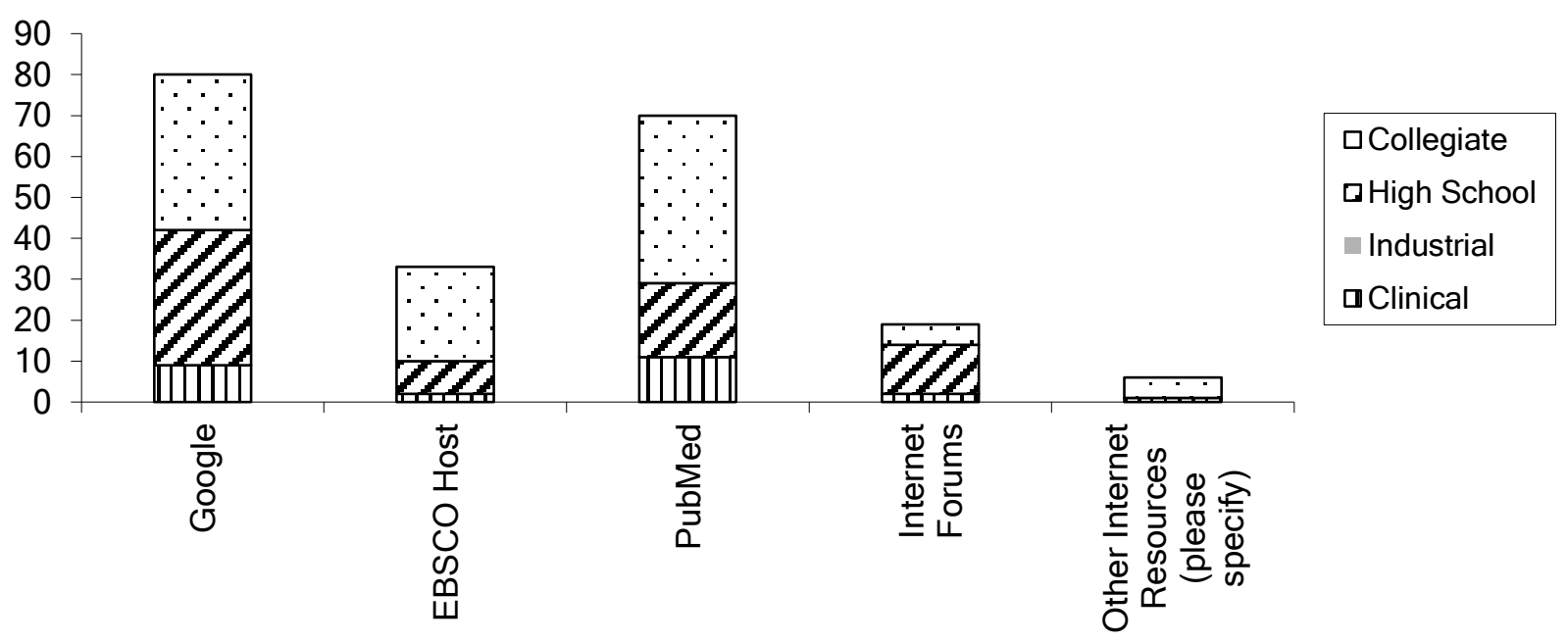


Figure D11. Resources Utilized for Scenario 5-CAI Rehabilitation

\section{What resource(s) would you utilize to obtain the necessary information to treat this athlete? (select all that apply)}

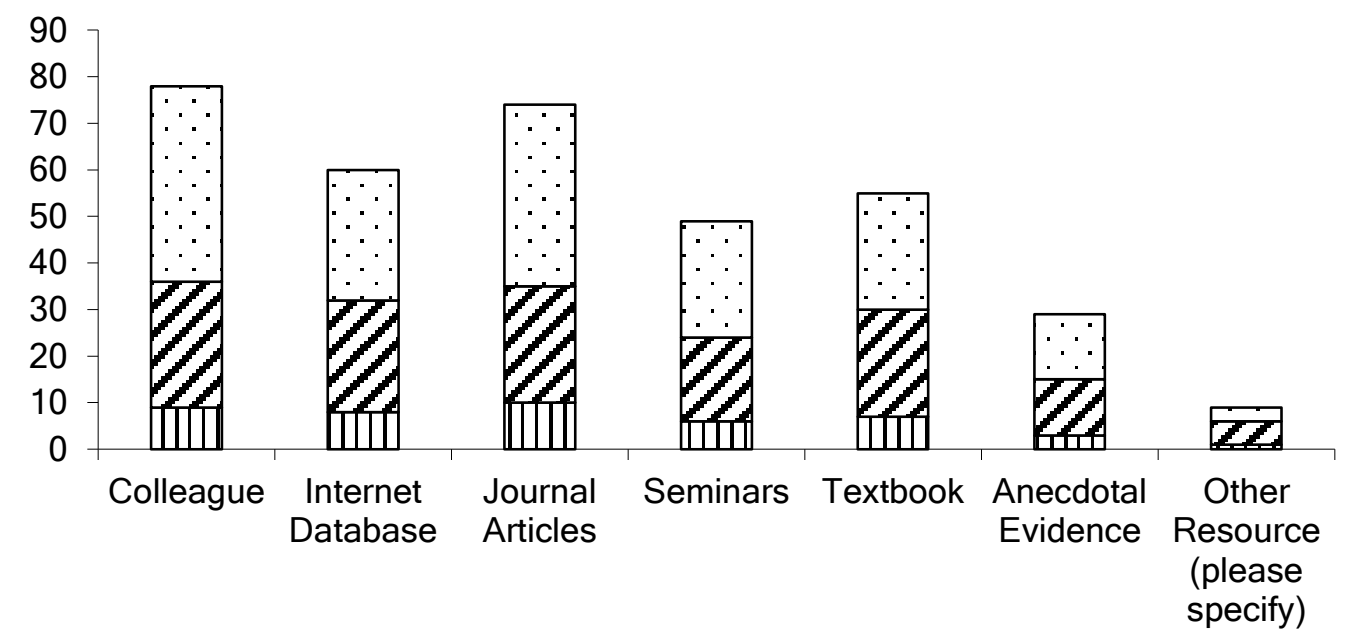

$\square$ Collegiate

¿High School

Industrial

๑ Clinical

Figure D12. Internet Resources Utilized for Scenario 5 - CAI Rehabilitation

What kind of internet resource(s) would you utilize to find applicable information pertaining to your clinical research question? (select all that apply)

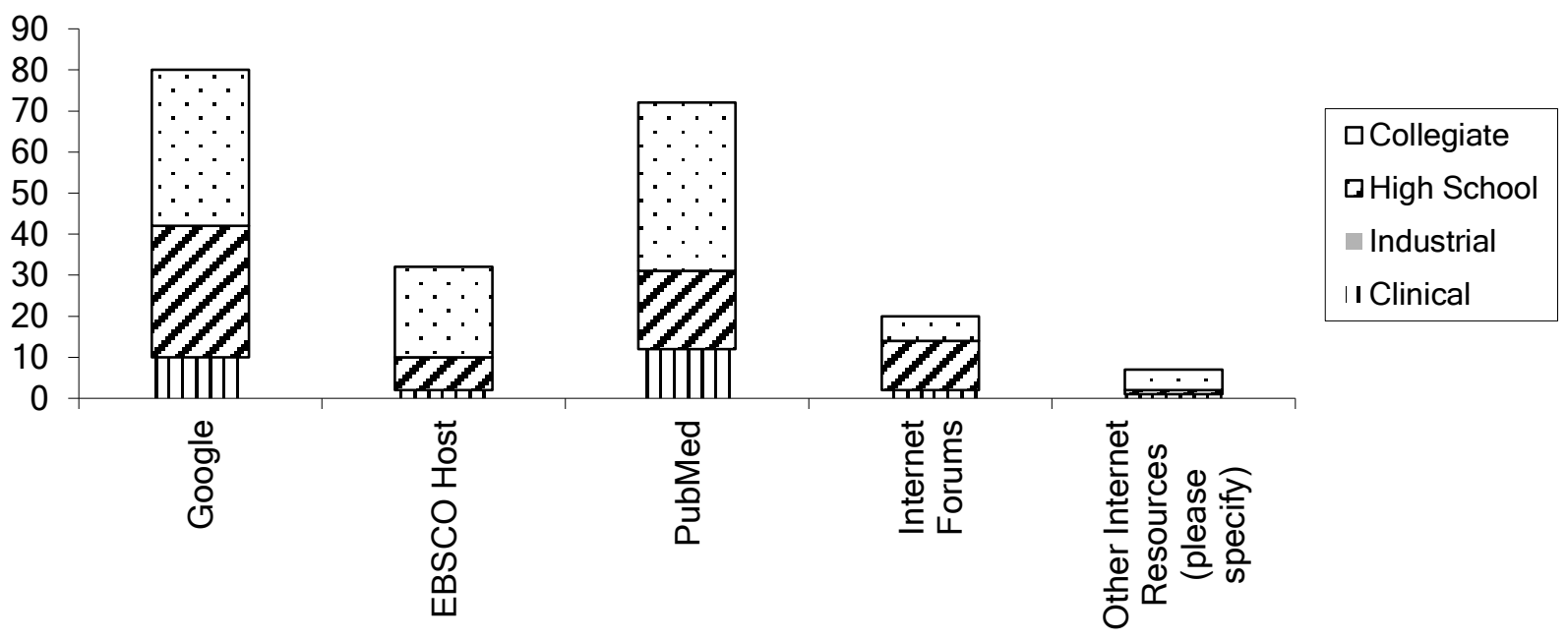




\section{APPENDIX E}

\section{RECOMMENDATIONS FOR FUTURE RESEARCH}

1. A recommendation would be to repeat this study with a greater sample size in order to gain statistically significant information regarding evidence based resources utilized and barriers to implementation among clinically practicing ATs.

2. Another recommendation would be to assess undergraduate students and graduate students to determine their ability to implement EBM concepts into clinical applications and whether they used more or less EBM resources compared to clinically practicing ATs.

3. Another recommendation is for further investigation of the obstacles between the conceptual knowledge of EBM and the clinical application.

4. Lastly, a final recommendation would be to assess how frequently ATs create clinical questions, how successful the AT is in finding information, and what factors are considered when selecting the appropriate professional literature for the patient population. 


\section{ADDITIONAL REFERENCES}

31. Denegar C. Advancing patient care: everyone wins. J Athl Training. 2008;43(4):341

32. Burns H, Foley S. Building a foundation for an evidence-based approach to practice: teaching basic concepts to undergraduate freshman students. J Prof Nurs. 2005;21(6):351357

33. Manspeaker S, Van Lunen B. Overcoming barriers to implementation of evidence-based practice concepts in athletic training education: perceptions of select educators. $J$ Ath Train. 2011:46(5):514-522

34. Mantzoukas S, A review of evidence based practice, nursing research, and reflection: leveling the hierarchy. J Clin Nurs. 2008;17(2):214-223

35. Schlonsky A, Gibbs L. Will the real evidence-based practice please stand up? Teaching the process of evidence-based practice to the helping professions. Brief Treat Crisis Interv. 2004;4:137-153

36. El Dib R, Atallah A, Andriolo R. Mapping the Cochrane evidence for decision making in health care. J Eval Clin Pract. 2007;13:689-692

37. Goldenberg M. Iconoclast or ceed? Objectivism, pragmatism, and the hierarchy of evidence. Perspect Biol Med. 2009; 52(2):168-187

38. Thabane L, Thomas T, Ye C, Paul J. Posing the research question: not so simple. Can J Anesth.2009;56:71-79

39. Richardson S, Wilson M, Nishikawa J, Hayward R. The well-built clinical question: a key to evidence-based decisions. ACP J Club. 1995;A-12-13

40. Ebell M. Information at the point of care: answering clinical questions. J Am Board Fam Pract. 1999;12(3):225-235

41. Stone P. Deciding upon and refining a research question. J Palliat Med. 2002;16:265-267

42. Schwartz A, Millam G, UIC LCS Investigators. BMC Med Inform Decis Mak. 2006;6:16

43. Heiwe S, Nilsson Kajermo K, Tyni-Lenne R, Guidetti S, Samuelsson M, Anderson I, Wengstrom Y. Evidence-based practice: attitudes knowledge and behaviors among allied health care professionals. Int J Qual Health Care.2011;23(2):198-209 
44. Choundry N, Fletcher R, Soumeral S. Systematic review: the relationship between clinical expertise and quality of health care. Ann Intern Med. 2005;142(4):260-273

45. Fineout-Overholt E, Mazurek Melnyk, Schultz A. Transforming healthcare from the inside out: advancing evidence-based practice in the $21^{\text {st }}$ century. J Prof Nurs. 2005;21(6):335-344

46. Jousimaa J, Makela M, Kunnamo I, MacLennan G, Grimshaw J. Primary care guidelines on consultation practices; the effectiveness of computerized versus paper-based versions: a cluster randomized controlled trial among newly qualified primary care physicians. Int J Technol Assess. 2002;18(3):586-596

47. Sauers E. Establishing an evidence-based practice culture: our patients deserve it. $J$ Athl Train Sport Health Care. 2009;1(6):244-247 